\title{
How good is survey design in medical libraries?: a systematic review of user surveys
}

\section{by}

\section{Rachel Margaret Esson}

Submitted to the School of Information Management, Victoria University of Wellington in partial fulfilment of the requirements for the degree of Master of Library and Information Studies 


\section{Acknowledgements}

I would like to acknowledge my supervisor Professor Rowena Cullen for her patience, help and support. I would also like to acknowledge the team at the Wellington Medical Library for making me welcome during the long hours of hand searching journals there. Last but not least I would like to thank my family for coping with my long absences and Dave in particular for moral support and proofreading. 


\section{Contents}

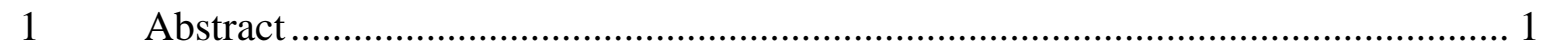

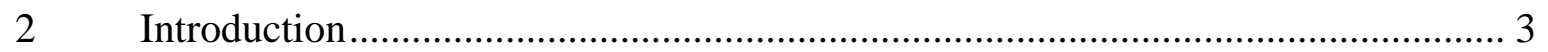

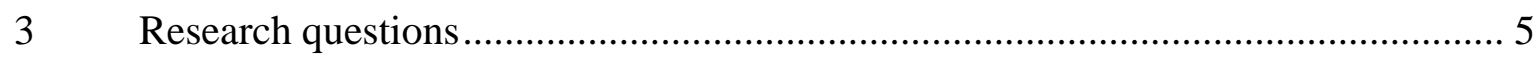

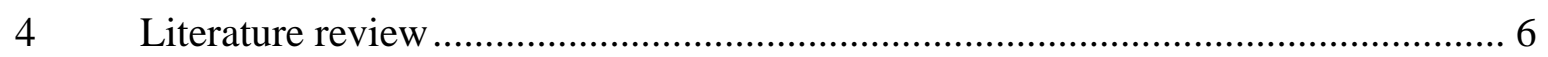

4.1 Measuring service ……………………………………………………... 6

4.2 Evidence-based library practice .................................................................... 9

$4.3 \quad$ Evidence-based practice and systematic reviews ………………………….... 14

4.4 Survey design .......................................................................................... 17

4.4.1 Aims of survey .......................................................................... 18

4.4.2 Survey method and delivery …………………………………..... 20

4.4.3 Pilot or pre-test............................................................................. 22

4.4.4 Ethical approval and confidentiality ……………………………..... 23

4.4.5 Location and setting ................................................................... 25

4.4.6 Population sampling and exclusion ................................................. 26

4.4.7 Pre-notification, and cover letter and sponsor …………………….... 28

4.4.8 Survey presentation....................................................................... 29

4.4.9 Number and type of questions asked ................................................ 30

4.4.10 Response rates................................................................................ 33

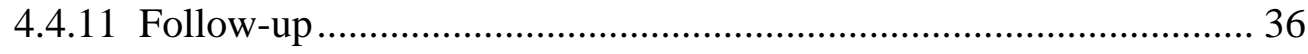

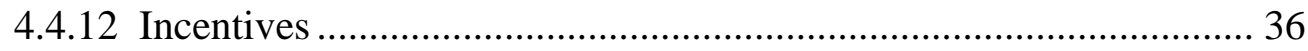

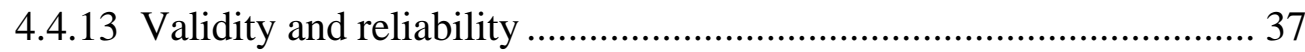

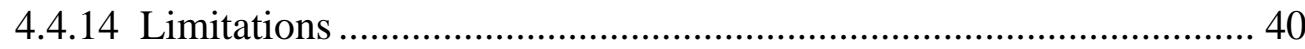

$4.5 \quad$ Doctors as survey population...................................................................... 40

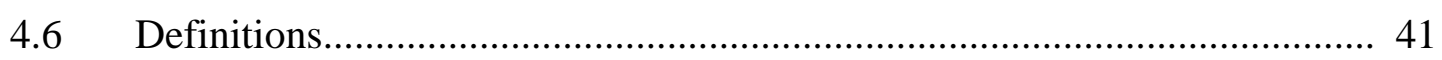

4.7 Summary ………………………………………………………… 42

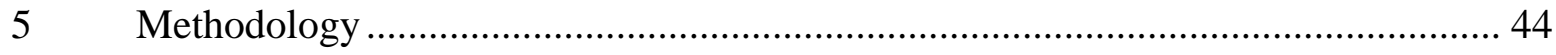

5.1 Inclusion/exclusion criteria ....................................................................... 46

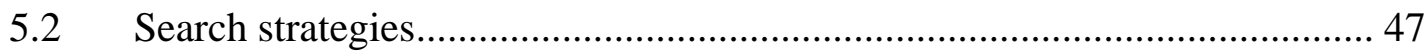

$5.3 \quad$ Methods of data analysis........................................................................... 51 


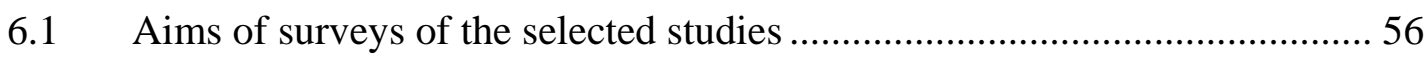

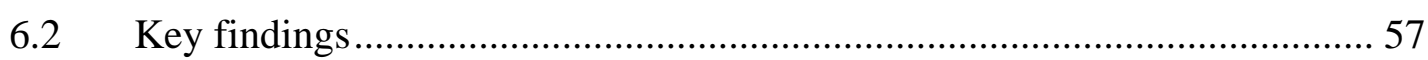

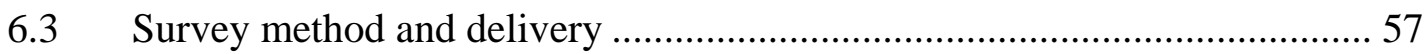

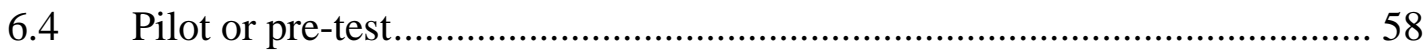

6.5 Ethical approval and confidentiality …...................................................... 58

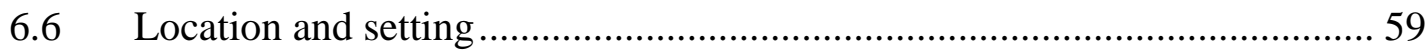

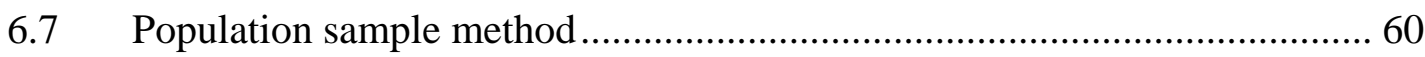

6.8 Pre-notification, cover letter and sponsor ................................................ 61

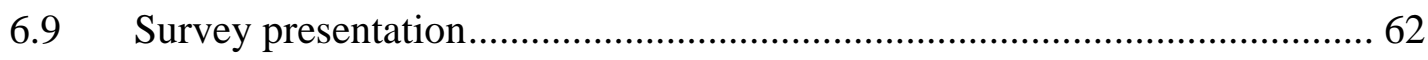

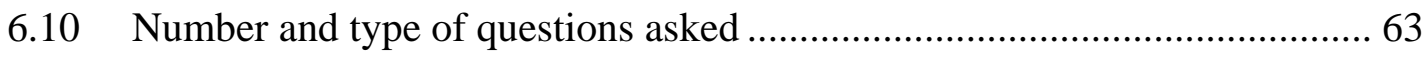

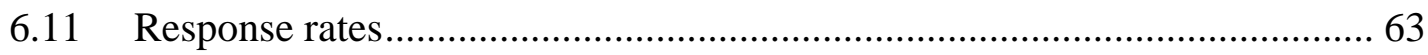

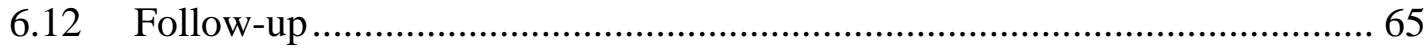

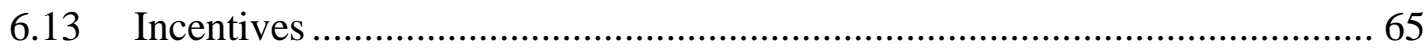

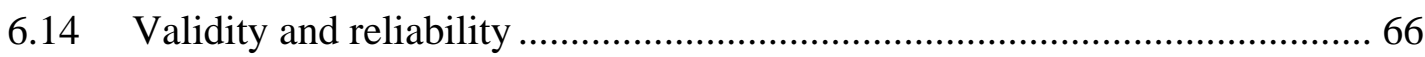

6.15 Limitations reported in selected studies................................................6 67

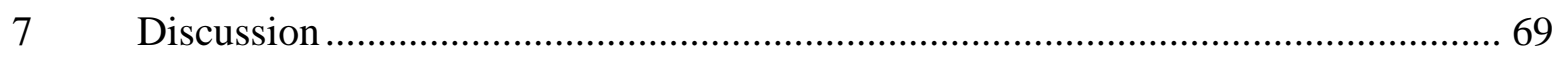

7.1 Reporting Survey Results Guidelines (Resurge) ..................................... 71

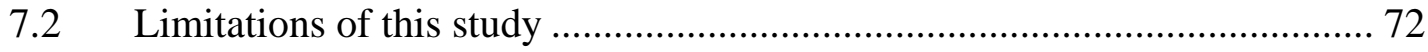

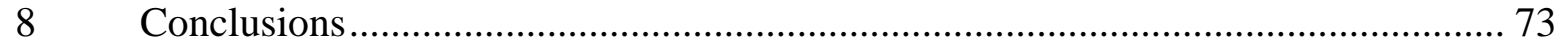

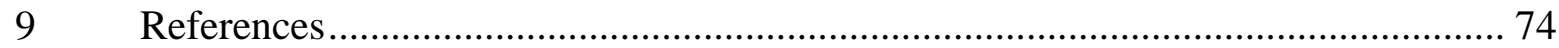

10 Appendix - Data extracted from studies 


\section{Abstract}

Introduction: Medical libraries very often base the decisions they make about library services on information gathered from user surveys. Is the quality of information obtained in this way sufficient to enable evidence-based practice?

Aim: To determine what aspects of user survey design and presentation obtain the best response rates and therefore high external validity. Also to provide guidance for medical librarians who may wish to carry out user surveys.

Methods: Library and information studies databases and Medline were searched to identify studies that reported the results of library user surveys that measured user perceptions of an existing library service or potential service. Studies that evaluated information skills training or clinical librarianship interventions were excluded as they have been looked in separate systematic reviews. Also studies that reported the results of LibQUAL or SERVQUAL were excluded.

Results: 54 studies were included. The quality of the majority of the surveys was not clear as the reporting of the methodology of the user surveys was poor. However, it was determined that, as demonstrated in previous research, paper format surveys reported higher response rates than online-only surveys. It was not possible to extract any relevant data from the identified studies to draw any conclusions relating to presentation of the survey instrument. 
Conclusions: Unless survey methodology is reported in detail it is not possible to judge the quality of the evidence surveys contain. Good survey design is key to obtaining a good response rate and a good response rate means the results can be used for evidence-based practice. A Reporting Survey results Guideline (Resurge) is recommended to help improve the reporting quality of medical library survey research.

Keywords: Library surveys, Medical libraries, Questionnaires, Survey response rates, Evidence-based library practice 


\section{Introduction}

Survey research is sometimes regarded as an easy research approach. However as with any other research approach and method it is easy to conduct a survey of poor quality rather than one of high quality and real value. (Kelley, Clark, Brown, \& Sitzia, 2003 p. 261)

When libraries evaluate, make changes to or introduce new services very often the first step in the process is to conduct a library user survey. The purpose of the survey is to gather information to inform the decisions to be made about the service in question. They are often designed in-house by librarians with no extra resources. If librarians are going to use surveys they must ensure that they design the best possible survey instrument so that they gather reliable and valid evidence.

Libraries are moving towards implementing evidence-based practice and medical libraries have been at the forefront of this (Brophy, 2006).

In the library context evidence-based practice has been defined by McKibbon as:

... an approach to information science that promotes the collection, interpretation and integration of valid, important and applicable user-reported, librarian-observed, and research driven evidence. The best available evidence moderated by user needs and preferences, is applied to improve the quality of professional judgments. (Cited in Booth \& Brice, 2004 p. 7)

This definition highlights that the "best available evidence" should be applied to decision making in evidence-based practice. This research study will look at whether user surveys carried out in medical library settings can claim to be the "best available 
evidence” on which to base library service delivery decisions. Survey research and questionnaires are widely used in libraries to collect information from library clients and there is plentiful literature to guide librarians in the design of good quality surveys (Booth, 2003, 2005; Charbonneau, 2007; Miller, 2004); however, there is little written that addresses the specific issues that librarians working in the health sector face when wanting to implement a survey to obtain information from medical professionals. Doctors have a moderate to low response rate to survey questionnaires (Olmsted, Murphy, McFarlane, \& Hill, 2005) so extra care must be taken by medical librarians when designing and administering surveys to this distinct population group.

This study will identify via a structured review of the medical library literature the methods of survey delivery and questionnaire design that give the best response rates in a medical library context. The study will aim to contribute to improving the quality of survey research as a research method for medical libraries. Enhancing the quality of the evidence gathered from user surveys will therefore improve the service delivery decisions made using this evidence.

The study will extract data from identified user surveys conducted in medical library settings and reported in the medical library literature from 1999 to 2008 to determine which methods will provide the highest response rates and therefore the most valid and reliable evidence. 


\section{$3 \quad$ Research questions}

- Are user surveys able to provide good quality evidence for decision making about library services in medical libraries?

- What factors lead to high quality user surveys?

- What methods of survey delivery and presentation used by medical libraries give the best response rates?

- What recommendations can be made to help with questionnaire development? 


\section{$4 \quad$ Literature review}

\subsection{Measuring service}

Why do librarians conduct survey research? The desire to measure the perceived performance of library services is often the trigger for conducting a survey. Obtaining information from library users about their perception of library services can inform decisions about the future development of those services.

Without clear and reliable information about what is happening within an organization and in its interactions with its customers and suppliers it is impossible to make well founded decisions to guide future development or even to monitor the effects of decisions that have been made in the past. (Brophy, 2006 p.xv)

Brophy (2006) goes on to emphasise in his introductory chapter in his book Measuring Library Performance that decision making should be based on "best possible evidence rather than on a managers experience or intuition” (p.xv).

As libraries are facing a future where they are competing more and more with an unmediated information environment (e.g. www.wikipedia.org) it is becoming more important than ever that they engage with potential users and find out their information needs and how best to meet those needs. As Cullen (2001 p.662) states "they must improve the quality of their services in order to survive”.

How then do libraries find out from their users and potential users what their information needs are and how those needs are being met? Traditional library measures were quantitative measures such as the number of volumes and number of 
periodical subscriptions. The number of people through the door, numbers of items issued and number of study spaces were also used as indicators of service quality. The measuring of things moving around the system has been called an “input-output definition of effectiveness” (Johnson, 1995 p.320) and it assumes that what is held by the library has intrinsic value and is of use to the library customer. Johnson (1995) goes on to say:

So the request to librarians to study what customers really need, want and perceive can provoke a vague sense of unease. It seems to place professional judgment and commitment at the periphery rather that at the center of library work. It appears to put more stock than may be warranted in a customer's ability to define what is wanted and needed. (p.319)

Library and information professionals have in the past designed library services based on what they think customers need rather than on what customers actually say they want. They have assumed a rather patriarchal role, deciding that customers don't always know what it is they want. "The enactment of the library's service is built upon not just what customers want at a given moment but what professionals have determined customers need for the long term.” (Johnson, 1995 p. 319)

Libraries have in the last decade been moving away from assessing their service quality based purely on traditional statistical measures such as collection size, circulation figures or gate counts. They are looking to gather data on user perceptions of library service in order to help them make better decisions about service provision. Cullen (2001) describes the emergence of the virtual university supported by a virtual library as a major factor for academic libraries to focus more energy on identifying and meeting customer’s expectations. 
Measuring service is certainly a complex issue and there are many approaches to measuring service in libraries. There are relatively straightforward approaches that might measure "how good library users feel after dealing with a library; it may include their likelihood to return to that library when they next need information" (Miller, 2004 p. 125). However the measurement may be more complex and try to take into account previous library experiences or try to measure the gap between perceived service quality and expected service quality as in SERVQUAL. The more complex the concepts that are being measured the more complex the instrument to measure the concepts will need to be.

Service quality is described by Hernon and Calvert (1996 p. 387) in terms of "reducing the gap between customer expectations and the service provided".

Medical and health libraries are also looking for methods to assess the extent to which the library services they are delivering are meeting the needs of their client group. One of the first studies in a medical context to look beyond outputs and investigate possible ways to measure value of library services by measuring impact on patient care was the Rochester study led by Joanne Marshall. Marshall (2007) comments in a recent article that, "upon reflection it appears that one of the main achievements of the Rochester study was that it took the plunge and moved beyond measuring basic inputs, outputs and outcomes to measuring value and impact.” (p. 7)

She goes on to comment that "Librarians have continued to use the Rochester study in a variety of ways over the years and the study continues to be cited and used to demonstrate the value of hospital libraries” (Marshall, 2007 p. 7). Although the Rochester study was not a randomized controlled trial it did use many study design features that gave it credibility and rigour in the health-care setting. Most importantly 
the subjects were randomised and the librarians involved in service delivery didn't know which physicians were participating in the study.

An improved awareness of the importance of rigorous research design became particularly important with the move towards evidence-based library practice. As Kyrillidou \& Cook (2008) write:

Ultimately, both of these perspectives, the descriptive-analytical one and the human-relations-behavioral one, contributed to an increased awareness of libraries as symbolic entities manifesting elements of effect of service, information control, and library as place that generate perceptions and expectations as library users come into contact with these entities. (p. 890)

\subsection{Evidence-based library practice}

Evidence-based librarianship uses evaluation of library research to inform change and decision-making. It makes explicit the process of evaluating the information on which we base our decisions. Evidence-based practice evolved out of clinical medicine, where the most common definition is taken from Dr David Sackett, one of the early proponents of evidence-based medicine. Sackett defines evidence-based medicine as:

The conscientious, explicit and judicious use of current best evidence in making decisions about the care of the individual patient. It means integrating individual clinical expertise with the best available external clinical evidence from systematic research. (Sackett, Rosenberg, Gray, Haynes, \& Richardson, 1996 p. 71)

The quality of survey research in medical libraries has an impact on decisions made using this research. As librarians move to using an evidence-based practice 
framework for making decisions about service development, they need to ensure that the evidence they are basing their decisions on is reliable and valid.

The term evidence-based medicine or EBM was coined in 1992 by Gordon Guyatt (Straus, Richardson, Glasziou, \& Haynes, 2005) at McMaster University. EBM was developed as a means of effectively integrating clinical research into clinical practice. The framework for carrying out EBM outlined by Straus and colleagues was based on a five-step process which can be summarized as follows:

1. Identification of a problem or question.

2. Finding, as efficiently as possible, the best evidence to answer the question.

3. Appraising the evidence for validity and usefulness.

4. Applying the results to a specific population.

5. Evaluating the outcome of the intervention.

This framework was implemented in general medicine and many other medical specialties began to "attach the term evidence-based to their titles, cardiology, pediatrics, surgery ...” (Eldredge, 2000 p. 289). The EBM framework then "broadened out into many other areas, most notably education and social sciences”(Brice \& Hill, 2004 p.19) and also into librarianship.

Evidence-based librarianship is still a relatively new concept, with the framework filtering through from health care to health librarianship (Rossall, Boyes, Montacute, \& Doherty, 2008). Crumley and Koufogiannakis (2002) describe evidence-based librarianship (EBL) as:

A means to improve the profession of librarianship by asking questions as well as finding, critically appraising and incorporating research evidence from library science (and other disciplines) into daily practice. It also involves 
encouraging librarians to conduct high quality qualitative and quantitative research. ( p. 62)

How can librarians determine whether evidence is 'high quality'? In evidencebased practice two of the most important tools for determining the quality of evidence are critical appraisal tools and levels of evidence. Critical appraisal is not examined here because as Booth and Brice argue, "the success of critical appraisal as a foundation for evidence-based librarianship depends on the production of rigorous and useable research studies” (Booth \& Brice, 2004). The objectives of this study are to focus on the production of robust research. It is, however, useful to look at levels of evidence to determine where survey research would currently sit in this hierarchy.

'Levels of evidence' (or the 'hierarchy of evidence') is a key aspect of the evidence-based practice framework. The concept of a hierarchy makes explicit the criteria for judging the quality of research or other evidence used in evidence-based practice. In 2000 Eldredge listed the following nine levels of evidence-based librarianship evidence in a hierarchy that closely follows the EBM levels of evidence. In this list ' 1 ' is high, i.e. considered the most rigorous evidence available.

1. Systematic reviews of multiple rigorous research studies.

2. Systematic reviews of multiple but less rigorous research studies, such as case studies and qualitative methods.

3. Randomized controlled trials (RCTs).

4. Controlled-comparison studies.

5. Cohort studies.

6. Descriptive surveys.

7. Case studies. 
8. Decision analysis.

9. Qualitative research (focus groups, ethnographic observations, historic, etc). (Eldredge, 2000 p. 292)

These levels of evidence have been developed to draw attention to the possible bias that is found in the lower levels of evidence. As Eldredge states:

Higher levels of evidence reflect the capacity of these types of research designs to minimize bias. Systematic reviews allow researchers to pose a clearly stated question and then search relevant evidence in the published or unpublished literature. Researchers then critically assess the available evidence to make a recommendation. (Eldredge, 2004 p.38)

To carry out EBL effectively you need good evidence, preferably from the higher levels of the evidence hierarchy. Good evidence has a transparent and reproducible method.

The EBL process provides a framework for making important decisions based upon the best available evidence. Each of the five steps in the process require librarians to integrate their professional experience in judging the relevance and appropriateness of the best evidence. (Eldredge, 2006 p. 351)

Despite the acknowledgement of the importance of good quality evidence the research methods most often used in library information science are usually from the lower levels of the hierarchy. Eldredge (2000) confirms that "studies reveal that library research relies primarily upon three levels of evidence; descriptive surveys, case studies, and qualitative methods”. (p. 294) 
The research method used most often is survey research (P Hernon \& Schwartz, 2000; Kuruppu, 2007). There has been a significant increase in experimentation, but a recent study by Hider and Pymm (2008) confirms that "the survey approach remains the predominant research strategy in both library science and information science.”(p. 108). They report that in 2005 survey research accounted for $30.5 \%(n=173)$ of the studies that they analysed to determine research methods. This was the highest percentage with the next highest method being experimentation at 20.8\% ( $n=118)$. However, the $30.8 \%$ figure was a substantial decrease from earlier articles that reported survey research at $40.1 \%$ and $41 \%$ in 1975 and 1985 respectively.

In the hierarchy of library-related evidence described by Eldredge (2000), research would fit in at level 6, i.e. 'descriptive surveys'. Some may argue that survey research could come even lower, as often the survey method is not reported well in the literature and this means it is not a straightforward matter to evaluate the quality of the study. An issue of major concern is that response rates are very often quite low (Burkell, 2003) which means the external validity, i.e. the extent to which the results can be generalized, will be low. Pickard (2007) discusses that external validity:

...is concerned with the extent to which findings from the investigation can be generalized to the wider context. This depends on the sample method used in the investigation and what extent it is 'representative' of the wider population. This is demonstrated by a statistical examination of probability; the significance of the sample is paramount and needs to be given considerable thought before the research is carried out. (p.21)

Equally though argument could be made that if the survey research was conducted and reported with accuracy and rigour then it could be considered to be 
evidence of sufficient quality to use in evidence-based decision making. As Eldredge (2000) proposes:

Some lower levels of EBL evidence may contain studies with higher-quality design methodological rigor than study designs ranked at the higher levels of EBL evidence. In this connection, a well-designed descriptive survey could have greater validity than a poorly designed or procedurally compromised randomized controlled trial. (p. 294)

Improving the reporting of survey research methods and the results could potentially improve the level of evidence for this type of research. Ensuring that the survey method is transparent and reproducible would go a long way towards making survey research easier to evaluate and therefore improving the use of the research in evidence-based librarianship.

\subsection{Evidence-based practice and systematic reviews}

Systematic reviews have developed in the medical literature as a tool for evidencebased practice; however they are also relevant for other disciplines. "As is other fields, systematic reviews of library and information science topics can answer questions in the field and inform best practices”. (Sampson, Daniel, Cogo, \& Dingwall, 2008)

McKibbon (2006) asks why systematic reviews are important to librarianship and answers that that they are important for two reasons:

First, they help us build and make sense of our own research base. Using systematic reviews we can more easily identify our strengths while finding out where gaps exist. Using information from systematic reviews, we can 
implement and justify valuable services and programs while stopping or bypassing those programs that have not been shown to be beneficial. A welldone systematic review means that individuals do not have to collect and analyze primary studies for every decision they make. (p. 205)

The second reason she identifies is that librarians have an important role to play in developing systematic reviews, as the quality of a review depends heavily on the comprehensiveness of the evidence identified for review.

Systematic reviews, like EBM, have their origins in the medical setting. Iain Chalmers, a maternity care physician, wanted to overcome the problem that many research studies were not of sufficient size and power to demonstrate an effect. He therefore explored techniques of systematic reviews in maternal and perinatal care, and was responsible for bringing together evidence from randomized controlled trials for different interventions and then synthesizing and summarizing them. Chalmers went on to create the first Cochrane Centre in Oxford (UK) in 1992. This has resulted in international agreement on principles and processes for systematic reviews and global resources called the Cochrane Library (Booth \& Brice, 2004). The Cochrane Library is developed by Cochrane Review Groups. The review groups are based around a particular health area and are made up of healthcare professionals from around the world who volunteer to participate in the groups and work towards preparation and maintenance of reviews. "The groups are co-ordinated by an editorial team who edit and assemble completed reviews into modules for inclusion in the Cochrane Library" (Cochrane Collaboration, 2009). A New Zealand branch of the Australasian Cochrane Centre was established in 2004 with the aim of promoting and supporting Cochrane activities throughout New Zealand (New Zealand Cochrane Fellow, 2009). 
Librarians are attempting to move towards an evidence-based approach to decision-making — evidence-based librarianship (EBL) — which means that they are becoming more aware of the short comings of the research available on which to base decisions and they are also becoming more aware of the need to conduct better quality research to add to the body of knowledge.

There is, however, still a gap between recognising the need for good quality research and conducting and reporting good quality research. A recent article in the Health Information and Libraries Journal (Rossall et al., 2008) discussed the research capacity in health libraries and suggested that librarians should build on the few existing examples of good practice "through better consideration of evidence-based methodologies, hierarchies of evidence, improvement of research skills and a collective endeavour to identify research priorities”. (Rossall et al., 2008 p. 159)

Medical librarians undertaking research to inform their practice are well positioned to take advantage of the work that has been done in the health sector to improve the quality of research. They work in an environment where there is a commitment to use good quality evidence to base decisions on. It is logical to suggest that a medical librarian wanting to improve service quality for library users should first find out the user's perceptions of the current service in order to have a baseline or some evidence on which to base suggestions for service improvement. This is the beginning of evidence-based practice.

An appropriate method for gathering the required information about the current perception of library services would be to conduct a descriptive survey using a questionnaire as the survey instrument. As Powell and Connaway (2004) discuss, "the basic purposes of descriptive surveys are to describe characteristics of the population of interest, estimate proportions in the population, make specific 
predictions, and test associational relationships. (They can be used to explore causal relationships)” (Powell \& Connaway, 2004 p. 87) (emphasis in original).

However, in order to ensure that the evidence gathered in this way is robust enough to base decisions on, the design of the survey itself should be evidence-based. The section below looks at the literature regarding survey design and suggests methods to maximise response rates in order to increase external validity.

\subsection{Survey design}

How do medical librarians ensure that the user survey they are intending to conduct is well designed? There are several important articles in the library literature that have addressed this issue and there are lessons to be learned from taking a closer look at these articles (Booth, 2005; Burkell, 2003; Charbonneau, 2007; Littleton, 2007; Miller, 2004).

There have also been many articles in the medical literature about designing survey instruments (Beebe, Stoner, Anderson, \& Williams, 2007; Burns et al., 2008; Edwards et al., 2002, 2005; Olmsted et al., 2005; Panacek, 2008; Smeeth \& Fletcher, 2002). Very often medical professionals are the population that is being surveyed in the medical library so it is important to take a closer look at the design of surveys recommended in the medical literature. Many of the techniques for increasing response rates to surveys have not been tested in a population of doctors, who “typically have moderate to low rates of survey participation” (Olmsted et al., 2005 p. 3947).

The article by Olmsted outlines the factors that distinguish clinicians from the general population: "they very often have demanding work schedules, their time is valuable and participating in a survey is often not seen as a priority” (Olmsted et al., 
2005 p. 3947). Olmsted also refers to the fact that physicians have "gatekeepers" in the form of receptionists and nurses who may try to protect the doctor from intrusions on their time, and notes that they may be frequently asked to participate in surveys which could also contribute to their reluctance to complete surveys. These factors make it particularly important for librarians intending to survey medical professionals to take extra care designing their survey instrument and methods of delivery to overcome as many barriers to response as possible.

This review of the literature discusses some of the factors that have been investigated in either the library or medical literature, or both, and proven to have some impact on improving design or influencing response rates.

As Pickard stresses, "Questionnaire design is a very serious business and can mean the difference between a high response rate that provides you with detailed data or a sad lack of data which puts you in the position of being able to say very little about your research question” (Pickard, 2007 p. 184).

\subsubsection{Aims of surveys}

The first step in designing a good quality survey is to clearly determine the reason for the survey and think about the research question to be answered. As Burns (2008) states, “[a] clear objective is essential for a well-defined survey. Refining initial research objectives requires specification of the topic, respondents, and primary and secondary research questions to be addressed” (p. 245).

Using a PICO approach to determining a well-structured research question is one approach that medical librarians could consider using. PICO (or PICOT) is a standardised format developed by the evidence-based medicine protocol as a way to 
help medical professionals structure clinical questions so they are searchable (Fineout-Overholt \& Johnston, 2005).

The structure of a PICOT question is $\mathrm{P}=$ Specific patient population (or in a library it would be the library users under consideration), I=Intervention of interest or issue of interest, $\mathrm{C}=$ Comparison of interest, $\mathrm{O}=$ Outcome of interest and $\mathrm{T}=$ Timeframe which may or not be appropriate. As an example, using the PICOT question format to structure a question to investigate a medical library issue relating to the use of Personal Digital Assistant (PDA) resources by doctors, the question could be as follows, "Doctors (Population) prefer to use information resources on PDAs (Intervention) compared to standard e-books (Comparison) in which circumstances (Outcome)?

The importance of a clear research purpose is confirmed by Kelley et al (2003) who state the following:

Good research has the characteristic that its purpose is to address a single clear and explicit research question; conversely, the end product of a study that aims to answer a number of diverse questions is often weak. Weakest of all, however, are those studies that have no research question at all and whose design simply is to collect a wise range of data and then to 'trawl' the data looking for 'interesting' or 'significant' associations. (p. 262)

Asking a good question comes from being knowledgeable about the area you want to research, by talking to others knowledgeable in the area, and by avoiding pitfalls such as those identified by Kelley (2003), “allowing a decision regarding methods to decide the questions to be asked; posing research questions that cannot be 
answered; asking questions that have already been answered satisfactorily” (Kelley et al., 2003 p. 262).

\subsubsection{Survey method and delivery}

Survey method and delivery will vary according to the purpose of the survey and the type and amount of information being sought. It will also depend on the resources, financial and human, that the researcher has for the project. Time may be another factor that will contribute to determining the method and delivery of the survey (Burns et al., 2008). However, despite these factors researchers should keep in mind the audience they are designing the survey instrument for and target the method and delivery to maximise the response rate from their intended participants.

The number of questionnaires administered online has grown significantly over the past ten years. The attractions of online surveys are clear. They are cheaper to administer in terms of physical resources (paper, postage, etc) and they have the added advantage of being able to be delivered to a diverse population group. As Hayslett confirms, "E-mail surveys have been shown to be particularly advantageous in terms of cost and speed” (Hayslett \& Wildemuth, 2004 p. 74). Online surveys have evolved with innovations in technology and can now be generated relatively simply and quickly. Hayslett again comments that web based surveys "seem to offer many of the same benefits as e-mail surveys, but with a much nicer graphic interface, and electronic forms that provide the means for a researcher to standardize how responses could be given” (Hayslett \& Wildemuth, 2004 p. 74). This evolution combined with ubiquitous email has enabled researchers carrying out survey research to deliver a questionnaire to participants that can be answered when it suits the participant. 
However, research has also shown that there is a downside to e-mail or webbased surveys. "Many studies have established the skew in demographics of Internet users” (Hayslett \& Wildemuth, 2004 p. 74). Surveying Internet users means some older people or those who can't afford computer or Internet access could be unintentionally excluded from the survey.

Another factor to be considered is the response rate for web-based or online surveys. Hayslett and Wildemuth's research comparing the effectiveness of webbased versus paper surveys found that "response rates for the web survey were not as high as with traditional survey methods” and concludes that although the advantages of web survey administration are alluring, researchers must use carefully designed follow-up procedures and avoid technology-related implementation problems to match the effectiveness of traditional paper surveys. (Hayslett \& Wildemuth, 2004 p. 74). This is confirmed in a study by Nulty (2008) that looks at survey administration in student populations: "in general ...online surveys do not achieve response rates that are even close to what is achieved with paper-based surveys”. The only exception reported in this study was lower response rates to the paper-based surveys that were given to distance students. The other surveys had been given to students in class, i.e handed out in a face-to-face interaction in this case: "[t]he data clearly show that faceto-face administration results in higher response rates” (Nulty, 2008 p. 3).”

Face-to-face administration of survey questionnaires is often not possible, particularly if the population is geographically dispersed; postal and online administration are more suitable in this case.

Postal and telephone surveys return higher than average response rates for physicians and the "use of certified mail and/or courier companies such as FedEx also 
enhances the importance of the mail out package, increasing the likelihood of physician receipt and cooperation” (VanGeest, Johnson, \& Welch, 2007 p. 314).

Studies also recommend including a self-addressed, stamped envelope and report that "an actual hand-applied stamp has been shown to increase response rates" (Totten, Panacek, \& Price, 1999 p. 28).

Research has suggested that mixed mode formats to give busy physicians a variety of options to respond to surveys may also increase the likelihood of a response (Lensing et al cited in VanGeest et al., 2007).

\subsubsection{Pilot or pre-test}

Almost every article written on survey design in both the medical library literature and the medical literature stresses the importance of the pre-test or pilot testing for survey instruments. "[W]henever using a new survey instrument, it should be pilot tested, particularly if it underwent only 'face’or 'content' validity” (Panacek, 2008 p. 64). Pickard stresses that it is particularly important when using open questions: "here it really is essential. Find out how a question performs before you even think about sending it off to participants” (Pickard, 2007 p. 197).

Choosing the pre-test group should also be done carefully. As Lee (2004) points out, "using library assistants for a pre-test may not be a good idea; these students typically have a greater understanding of library jargon and may not be a good substitute for the general user” (p. 212).

An article by Presser et al (2004) acknowledges the value of pre-testing as the only way to evaluate questionnaires before conducting a survey, but it also warns that although a pre-test helps to identify problems that some questions may cause respondents there has been little research into how much impact revising questions 
actually has on improving questionnaires: "not a great deal is known about many aspects of pretesting, including the extent to which pretests serve their intended purpose and lead to improved questionnaires” (Presser et al., 2004 p. 109).

Presser et al (2004) also discusses that very often published reports of surveys fail to include information regarding methods of pre-testing or even whether pre-testing actually occurred: "published survey reports usually provide no information about whether questionnaires were pretested and, if so, how and with what results" (Presser et al., 2004 p. 109).

\subsubsection{Ethical approval and confidentiality}

There is some argument about the necessity of gaining ethics approval for one-off data collection methods such as questionnaires, particularly when participation in the survey voluntary. However, ethical approval is particularly important in the health sector and questionnaires that survey doctors should be transparent about the ethical approval process that they have been through, as physicians may judge the quality of the survey by the ethical approval process it has been through. "[T]he health information sector has extremely rigorous codes and it is usual for any research proposal to go before a committee before research can begin” (Pickard, 2007 p. 72).

Obtaining ethical approval, or being explicit that it was not required, is part of establishing credibility for the research to be carried. A cover letter to be sent with the survey instrument should also clearly state the researcher's affiliation and declare any conflict of interest. Powell and Connaway (2004) advise that "[t]he cover letter or opening statement should also disclose the researcher's affiliation and the project's sponsor and identify any possible harm or benefits for subjects” (p. 70). 
Confidentiality is another aspect to consider with survey design. Confidentiality "means that the identity of the participant will not be revealed when using any data provided by that participant” (Pickard, 2007 p. 77). Pickard goes on to make the distinction between anonymity and confidentiality: “Anonymity means nobody knows who the participant is; confidentiality means nobody will be told the identity of the participant.” (Pickard, 2007 p. 77). Anonymity can be more difficult and more costly to ensure than confidentiality, so unless it is absolutely necessary (i.e. a very sensitive topic) confidentiality should be preferred to anonymity.

Again it is particularly important to assure confidentiality to potential respondents in a medical library setting, as Van Geest asserts that "physicians will generally not complete a survey when they have concerns about the confidentiality of the results.” (VanGeest et al., 2007 p. 304).

Participants in survey research should also be kept informed regarding how their confidentiality will be maintained and what will ultimately happen to the data they have contributed to. Advice from Powell and Connaway (2004) includes the following statement:

The consent form which many subjects must sign should spell out the mechanisms by which that confidentiality will be protected and the extent to which it will be breached ... The schedule for the destruction of notes, tapes, computer files and other records should also be included. (p. 188) 


\subsubsection{Location and setting}

This study was unable to find any examination in the library literature of the impact of the country that a medical library is located in on response rates. It is likely, however, that there will be more reports of survey research conducted in the United States (USA) and the Untied Kingdom (UK) because those countries are where the publishers of the major medical library journals are based. Health Information and Libraries Journal is published in the UK and Journal of the Medical Library Association (JMLA) is published in the USA.

The setting for medical libraries includes libraries in hospitals, libraries in academic medical faculties, and medical libraries that are not part of academic faculties but attached to hospitals that have a teaching responsibility, usually at the postgraduate or speciality level. These hospitals are often referred to as teaching hospitals. The setting or context for a survey questionnaire can have an impact on response rate. The methodology review conducted by Edwards et al (2007) found 14 trials that looked at the effect on responses when the surveys "originated from a university rather than an alternative source, such as a government department or commercial organisation” (p. 6). There was an increase in response rate when the questionnaires originated from a university. Many medical libraries are part of medical academic faculties and it would seem likely based on the review by Edwards et al (2007) that response rates to questionnaires sent by academic medical libraries would be higher than those sent by hospital libraries without university affiliation although there does not appear to be any research that has addressed that specific issue. 


\subsubsection{Population sampling and exclusion}

How should librarians select the sample of users (or non-users) to invite to complete the questionnaire? There are several methods that are used but the important element to consider is to make sure that the sample selected will be able to provide answers to the questions that will fulfil the aim of the survey. As Burns (2008 p. 245) states "ultimately, the sampling technique will depend on the survey objectives and resources”.

Sampling provides a way to gather information from a representative group of the whole population, as it is often not practical or manageable to administer a questionnaire to a whole population. Simple random sampling is described by Pickard as "a procedure of creating a sample where each member of the defined population has an equal chance of being selected for inclusion and the selection of one participant depends on the selection of any other from that population” (Pickard, 2007 p. 61). Random sampling is a type of probability sampling.

Random sampling is the preferable method for selecting a population for research because it increases the likelihood that the sample selected is representative of the whole population and the results therefore can be generalised to that population.

However, although it is the more scientific and preferred method in the library survey research, non-probability or purposive sampling is the method used most often in user surveys. Non-probability sampling means that it is not possible to state with degree of certainty "the probability of a specific element of the population being included in the sample” (Powell \& Connaway, 2004 p. 94).

This means that it is not possible to generalise from non-probability samples as there is no assurance that the sample is representative. However, Powell and 
Connaway do acknowledge that there advantages with this forms of sampling and cases where it is appropriate to use this method "nonprobability samples are usually easier and cheaper to obtain than are probability samples, and for some purposes, such as where the focus is on the sample itself, may be quite adequate” (Powell \& Connaway, 2004 p. 94).

The main types of non-probability sampling are described by Powell and Connaway (2004) as “accidental”, “quota”, “snowball”, “purposive”, “self-selected” and “incomplete".

Accidental refers to the researcher selecting the respondents at hand until the specified size required for the sample is reached. The example they give for this is "if one wished to conduct an academic library user study, one might elect to survey library patrons as they entered or exited the library, on a 'first-come, first-served' basis. There would be little or no preferential selection of respondents” (Powell \& Connaway, 2004 p. 94). Quota sampling is seen as an improvement over accidental sampling in that it attempts to ensure that the diverse elements of the total population are included in the sample. Powell and Connaway (2004) note that "quota sampling is often used for public opinion surveys” (p. 95).

Snowball sampling occurs when respondents are asked to help identify other potential respondents. “This type of sampling is cumulative, hence the name snowball sample”(Powell \& Connaway, 2004 p. 95). Purposive sampling is when a sample is deliberately selected for specific purpose; the researcher is making an assumption the sample is reasonably typical of the whole population. However, as Powell and Connaway point out, "there is no assurance that a purposive sample is actually representative of the total population. Any sampling method not utilizing random selection is overly susceptible to bias” (Powell \& Connaway, 2004 p. 96). 
Self-selected sampling involves a group of people who have chosen to respond to an approach by researchers for participants in a research project: "there would be a strong possibility that these volunteers would not be representative of the entire population to which they belong” (Powell \& Connaway, 2004 p. 95).

An incomplete sample is not originally intended to be a non-probability sample but for a variety of reasons the total population may not have an equal chance to be selected to respond. This may be due, for example, to an incomplete population list which would render the sample unrepresentative and in effect a non-probability sample.

Despite the disadvantages of non-probability sampling it is important to remember that a "carefully drawn sample from a well-defined population can provide the data necessary to answer important research questions” (Totten et al, 1999 p.26).

\subsubsection{Pre-notification, cover letter and sponsor}

The Cochrane systematic review conducted by Edwards et al (2005) found that "the odds of response were substantially higher with pre-notification" and that "odds of response were also increased with personalised questionnaires" and "university sponsorship”. These findings were verified by VanGeest et al (2007) in a more recent, smaller study that was carried out with physicians: "Three studies found that a personalised cover letter and/or the inclusion of a handwritten note resulted in significantly higher response rates” (p. 311).

Given that there is clear and verified evidence that these simple interventions increase response rates it would be reasonable to expect that medical library user surveys could take advantage of these recommendations summarised by VanGeest et al (2007) as follows: 
Collectively, personalised cover letters and/or mailout packages had a weighted overall effect size reflecting an association with higher physician response. Direct contact (e.g. prenotifiation calls and/or letters in advance of a survey and follow up contact) is another mechanism to personalise a survey that often results in improved physician response. (p. 311)

When considering sponsorship for a survey it may be wise to pre-test the sponsor, as not all sponsors achieve the desired increase in response rate as in the study by Bhandari described by VanGeest: “Although organisational sponsorship generally improved participation, a study supported by expert surgeons actually resulted in a lower response rate, suggesting possible 'limits of leadership' related to collegial sponsorship” (Bhandari cited in VanGeest et al., 2007 p. 311).

\subsubsection{Survey presentation}

Appearance and content are extremely important if you want to encourage responses: your questionnaire has to look good and read well, your instructions need to be clear and plausible. (Pickard, 2007 p. 184)

There have been several investigations into the physical presentation of questionnaires, particularly for paper format questionnaires (Beebe et al., 2007; Edwards et al., 2002, 2005). There is evidence that a small increase in response rate can be achieved by using "coloured as opposed to blue or black ink” (Edwards et al., 2005 p. 2). Beebe et al (2007 p. 1185) reported a study where “ a small (6 1/8 x 8 1/4 in) questionnaire booklet on white paper had a higher response rate (68.4\%) than a similarly sized questionnaire on blue paper (62.3\%).” The Beebe study also “observed a favourable response rate for a large questionnaire printed on blue paper” (Beebe et al, 2007 p. 1185); however the size of the increase was relatively small and the 
authors recommended using the small white format for the questionnaire if time and resources were an issue. Other studies have investigated further presentation issues for print format surveys, such as single or double-sided printing, attractive layout and paper quality: "the use of an attractive business letter format and standard-sized questionnaire booklets ... associated with higher response rates. Paper quality of the other hand was not associated with increased physician cooperation” (VanGeest et al., 2007 p. 310). VanGeest also reported no difference in response rates comparing single and double-sided printing.

Burns (2008) makes recommendations for the presentation of online format surveys. Questions should be "presented in a single scrolling page (single-item screen) or on a series of linked pages (multiple-item screens) ... and the use of radio buttons may decrease the likelihood of missing data compared with entry boxes” (p. 247).

\subsubsection{Number and type of questions asked}

The type and quality of the questions used in the survey instrument can have a huge impact on response rate and also on validity. The two main types of questions used in surveys are "open” and “closed”. “Open” questions are ones where a free text answer is possible and "closed" questions have a structured response option. "Closed" responses include formats such as yes/no and they may also include a scale or ranking items in a list or choosing from a list of items. There is some debate about whether closed or forced questions should include "don't know" options to cater for uncertainty. Miller in her 2004 article states that if "you wish to measure the level of satisfaction, respondents must have an opinion about the statement. They cannot be allowed to be fence sitters.” (Miller, 2004 p. 128). While the article by Burns (2008) acknowledges that an option for an indeterminate response could be seen as letting 
respondents "off the hook" it is sometimes important to provide an option for uncertainty and in certain cases, such as when measuring respondents' knowledge rather than attitudes, it is crucial to provide that option. Burns (2008) also suggests providing an "other" or requesting "any other comments" as a way of providing for unanticipated answers and also suggests that during question testing the "other" option "can help to identify new issues or elaborate on closed response formats" (Burns et al., 2008 p. 247).

It may also be appropriate to give an option for "declined to answer" so that it is apparent that the respondent chose not to answer the question rather than leaving it blank so it could appear that the question had just been missed (Panacek, 2008).

Pickard warns that it is "notoriously difficult to encourage respondents to complete great sections of blank lines in their own words, it demands too much thought and therefore too much time” (Pickard, 2007 p. 186).

This is confirmed by VanGeest who reports a study "that examined open versus closed-ended questionnaire formats on physician response. The closed-ended questionnaire format resulted in a $22 \%$ higher cooperation rate compared with the open-ended format” ( Griffith, Cook, Guyatt \& Charles cited in VanGeest et al., 2007 p. 310).

Question order can also have an impact on response and completion. Recommendations from several studies suggest putting less threatening questions at the beginning of the survey and leave possibly problematic questions until later:

The order of questions can be important. Questions that individuals might object to answering outright should be put towards the end of the survey. Start with questions that are less threatening or inflammatory and 'warm up' to 
answering more problematic questions. This increases the pleted (sic) most of a survey, there is a vested emotional interest in completing the rest, even if later questions are less comfortable. (Panacek, 2008 p. 64)

In 2008 Drummond et al confirmed this advice in a study carried out with a population of primary care physicians. The study concluded that "[o]rdering questionnaires with general questions first can significantly increase response rates, whereas precontact can achieve a modest increase. These strategies may enhance response while adding little to the cost of a physician survey” (Drummond, Sharp, Carsin, Kelleher, \& Comber, 2008 p. 177).

Avoiding jargon and abbreviations and keeping questions clear and simple is also recommended. Questions should also be phrased in a culturally sensitive, gender neutral way. Burns et al (2008) advises that “[q]uestion’s stems should contain fewer than 20 words and be easy to understand and interpret, nonjudgmental and unbiased” (p. 246). Avoiding absolutes such as “never” or “always” is also suggested.

It is extremely important that each question focuses on only one concept. When designing a questionnaire and being conscious of keeping it as short as possible (more on this later) it is tempting to cover two concepts with one question. Booth (2005) gives the following example of a compound question:

we encounter questions such as 'do you require information or training on the MEDLINE database?' Where a respondent completes the answer 'Yes' we are not able to discern if they are saying 'Yes' to information, 'Yes' to training or 'Yes' to both. (Booth, 2005 p. 230)

Pickard also recommends including a variety of questions to prevent respondents from getting bored — a mixture of open and closed questions works well. 
Taking into consideration the collection and analyzing of the data is also important when planning the type of questions to use in a questionnaire. "In general close-ended questions are easy to tabulate and analyze because respondents must chose from among the offered alternatives” (Charbonneau, 2007 p. 49).

Number of questions is also important and this can have a significant impact on the response rate: "lengthy questionnaires are less likely to be completed" (Dillman cited in Burns et al., 2008 p. 246). The length of the questionnaire is particularly important when surveying a population that includes busy clinicians. When faced with a heavy case load or queues of patients in the waiting room a doctor may be less likely to complete a questionnaire no matter how important the research.

"Physicians may be reluctant to participate in surveys, even when a survey requires relatively little effort to complete” (Olmsted et al., 2005). When designing surveys intended for doctors, librarians should take particular care to keep them as brief as possible to enhance the likelihood of response.

\subsubsection{Response rates}

It is well accepted that high response rates to survey questionnaires are a safeguard against low generalisability (Burns et al., 2008; Edwards et al., 2007). Smeeth \& Fletcher confirm that "no matter how expensive, well designed, or important a study, a poor response rate can introduce such uncertainty — and worse still, bias - in the results as to make the study of little scientific value” (p. 1168).

There has been much discussion and debate in the literature (Burkell, 2003; Burns et al., 2008; Totten et al., 1999) about what is an acceptable response rate for survey research. Totten et al (1999) propose that "a desirable target response rate should be at least 75\%”, they also add that to publish survey results in major journals 
a survey rate of closer to $90 \%$ is often required. The Canadian Medical Association journal's editorial policy requires a response rate of not less than $60 \%$ for surveybased research (Draugalis, Coons, \& Plaza, 2008).

Burkell's 2003 study of three major library and information science journals (Public Libraries, College \& Research Libraries, and Library \& Information Science Research) from a six-year period revealed "an average response rate for the surveys identified ... [of] $63 \%$, a value that is comparable to the average response rate of $61 \%$ observed for surveys of physicians over the years 1986-1995” (p.254).

Burkell (2003) also observes that the highest response rates are those obtained from surveys of librarians and the lowest from surveys of user groups. She relates this to the intrinsic interest of the survey to those completing them. "Because the general focus of research published in LIS is libraries and information services, it seems likely that libraries and librarians would be more interested in the topics than would be members of user groups” (p. 254). It is likely therefore that medical libraries conducting user survey research could expect response rates at the lower end of the averages reported by Burkell.

Discussion regarding response rates should also take into consideration whether the non-responders may have been significantly different from the survey responders:

[P]hysician surveys are characterized by low response rates, raising concerns about the validity and generalisability of their findings. Specifically, low response rates raise concerns about nonresponse bias or the likelihood that nonresponding physicians will be systematically different from the population under study. (VanGeest et al., 2007 p. 302) 
Following up with a subset of nonresponders is one recommendation for dealing with nonresponse bias. "The same questions written on the mail survey simply are asked by phone. If the answers in a random subset of nonresponders are not different from the responders, nonresponder bias may not exist” (Totten et al., 1999 p. 29). Burkell's (2003) article on nonresponse in the library literature observes that the issue of nonresponse is significant for library survey research: "almost three quarters of the surveys examined had response rates less than $75 \%$, a level that is traditionally held to be required for generalization from sample to population” (Burkell, 2003 p. 254).

Medical librarians, like all researchers conducting survey research, must be aware of the issues of nonresponser bias and either take steps to minimize the bias or at least acknowledge and document how it was dealt with.

An interesting consideration for librarians surveying physicians is that reviews have identified "smaller-than-anticipated differences between physician respondents and nonrespondents ... suggesting low rates of nonresponse bias” (VanGeest et al., 2007 p. 315). The similarity of physician training, knowledge and attitudes is a possible explanation offered for this result.

However, it is still extremely important for researchers to clearly report the response and nonresponse rates when publishing survey results:

At a minimum the investigator must document the percentage of nonrespondents and note the number that are a result of mechanical factors, such as outdated addresses or job changes. (Totten et al., 1999 p. 29)

It is a concern to note that a review of the quality of survey reports in nursing literature (Badger \& Werrett cited in Burns et al, 2008) found response rates reported 
in only $51 \%$ of the studies. It is essential to accurately report the response rate for surveys to enable readers to evaluate the validity of the research.

\subsubsection{Follow-up}

Initial response rate to print surveys can often be quite low. Follow ups are considered a crucial method to increase the response rates (Burns et al., 2008; Edwards et al., 2002, 2005; Totten et al., 1999). "In general, mailed surveys have a low first-pass response rate, and repeat mailings will be necessary because you want to achieve a high response rate for statistical validity” (Totten et al., 1999 p. 27).

Totten et al. suggest three reminders at 2-4 week intervals, and including another copy of the questionnaire is also suggested. Edwards et al. (2002) suggest from their research that "follow up contact with non-respondents saying that the sponsor will benefit if participants return questionnaires, and saying that society will benefit if participants return questionnaires” has a significant positive impact on response rate.

The number of follow ups may depend on factors such as budget for the survey but generally reminders are a cost-effective way to increase responses. As Burns et al. (2007) discuss, “[r]eminders have a powerful and positive influence on response rates. For postal surveys, each additional mailed reminder yields about $30 \%-50 \%$ of the initial responses” (p. 250), so is clearly a worthwhile strategy for librarians to employ to improve response rates.

\subsubsection{Incentives}

The have been numerous studies that have conducted research into the effect of incentives on response rates (Burns et al., 2008; Edwards et al., 2007) and they are in agreement that an incentive in most cases has a positive effect on response rates. As discussed by VanGeest et al. (2007) “... even modest \$1 incentives were associated 
with higher response rates among physicians when comparing physicians receiving no incentive. With regard to larger incentives the results are mixed” (p. 306). The larger incentive may appear to respondents to be manipulative.

The timing of the incentive to encourage participation in surveys has also been investigated in detail. Clear evidence has been produced to show that offering modest monetary incentives at the time of the survey, rather than upon completion, does have a positive impact on rate of response. "Incentives should be offered (preferably a small amount of money with the questionnaire” (Edwards et al., 2005 p. 2). VanGeest et al. (2007) confirm that "prepaid monetary incentives are ... superior to promised incentives.” (p. 306) and Totten et al (1999) backs this up stating "many researchers believe bias is minimized and response rates improved if the incentive is offered to everyone up front rather than providing it later as a reward for returning the survey” (p. 28).

\subsubsection{Validity and reliability}

Lee (2004) describes validity as the "ability of survey questions to accurately measure what they claim to measure. An item designed to measure customer awareness of a given service should measure awareness and not another related concept” (p. 211).

There are four types of validity that survey instruments are concerned with: face, content, construct and criterion (Burns et al. 2008). Face validity is when "experts and sample participants evaluate whether the questionnaire measures what it intends to measure” (Burns et al. 2008 p. 249). This usually occurs during pre-testing or piloting of the questionnaire. Content validity according to Burns et al. (2008) is best tested by experts who are able to "evaluate whether the questionnaire content accurately assess all fundamental aspects of the topic” (p. 249). Construct validity is described as being 
"the most abstract validity assessment. It should be evaluated if specific criteria cannot be identified that adequately define the construct being measured” (Burns et al., 2008 p. 249). Criterion validity is when "responses to survey items are compared to a gold standard” (Burns et al., 2008 p. 249). At a minimum Burns et al. (2008) suggest that a questionnaire should be tested for face validity.

There is one further type of validity that concerns surveys and that is external validity or "the extent to which findings from the investigation can be generalised to the wider context” and depends largely on the sample used and how representative it is of the wider population (Pickard, 2007 p. 21). If the response rate to a survey questionnaire is low, then unless steps have been taken to address nonresponder bias, the results will have low external validity. Burkell (2003discuses how library and information science researchers could improve the way they deal with nonresponse bias and states that "only a small proportion of studies acknowledged the possibility of sampling bias caused by nonresponse and attempted to assess or correct for that bias” (p.254).

However, Powell and Connaway (2004 p. 119) state that although survey research has limitations in terms of internal validity if it is based on probability sampling and achieves a high response rate, it could be "strong in external validity". They go on to explain, "this is due to the fact that survey research generally concerns itself with naturally occurring variables in natural settings” (Powell and Connaway 2004 p. 119).

It is possible for a measure to be reliable but not valid but it is not possible for a measure to be valid if it is not reliable. An example that is often given is that of a thermometer that does not accurately read temperatures. It may give temperature readings that are several degrees too high but if it does this consistently then it is 
reliable but because it is not accurate it is not valid. However, a broken thermometer that is not reliable and gives readings that fluctuate widely is neither reliable nor valid. “Reliability is a necessary but not sufficient condition for a valid survey” (Lee, 2004 p. 212). In a study examining core epidemiology journals, “only $47 \%$ of articles even discussed validation; of these only $67 \%$ actually validated questions used in the study” (Rosen \& Olsen, 2006 p. 1145). The authors concluded by recommending greater sharing of questionnaires to allow researchers using questionnaires more chances to validate and test reliability of the instruments. This plea is echoed in the library literature by Booth, who suggests that the very basis of evidence-based practice is about learning from the successes and failures of others: "[w]hy do we insist on believing that any librarian can successfully design a questionnaire?” (Booth, 2005 p. 228) (emphasis in original).

Reliability refers to how consistently a measure performs. Often a test-retest method is used to establish reliability (Pickard, 2007). If research conducted by other researchers reports results that are significantly similar then reliability is accepted.

Reliability in questionnaires can be low if questions are designed poorly and could be interpreted differently by respondents. Lee points out in her article that "[i]t can be very easy to damage a survey's reliability. Wording that may be clear to the writers of the survey may be confusing or easily misinterpreted to the end user” (Lee, 2004 p. 211). Often to improve reliability the same concept is asked in several different ways (LibQUAL is a good example of this reliability strategy). 


\subsubsection{Limitations}

It is important to keep in mind that even if librarians employ all the modifications that have been shown to improve response rates for questionnaires, this type of research is still "relying on the honesty and accuracy of self-reported data; this is the nature of the questionnaire” (Pickard, 2007 p. 200). "The use of questionnaires in research is based on one basic underlying assumption: that respondents will be both willing and able to give truthful answers” (Burns cited in Pickard, 2007 p. 183).

Self-selecting bias is another aspect of this data collection technique to be aware of and of course as discussed in the relevant section above low response rates can be a huge limitation particularly if no attempt is made to establish if non-respondents are significantly different from respondents.

\subsection{Doctors as survey population}

The growth in evidence-based practice in medicine over the last ten years has had a corresponding growth in research. Drummond et al. (2008) describe the situation in Ireland:

National surveys of the knowledge and practices of primary care physicians are becoming increasing common. However, for primary care physicians, participation in research has to compete with other priorities and there is a danger that increasing research demands will lead to 'research fatigue'.

(p. 178)

When using a survey methodology with medical professionals it may be acceptable to accept a lower than hoped for response rate, and if the investigators can 
be assured that the respondents were representative then the lower response rate may suffice. As noted in the research reported by VanGeest the smaller than expected differences in respondent and nonrespondent doctors means that nonresponse bias may not be such an issue for lower than generally accepted response rates (VanGeest et al., 2007).

There are also unique incentives that appear to help encourage medical professionals to respond to questionnaires. "In one study, the opportunity to receive continuing medical education (CME) credits was deemed to be an effective motivation for physician participation in a mailed questionnaire” (VanGeest et al., 2007 p. 308).

\subsection{Definitions}

For the purposes of this study the following definitions are used. Medical Libraries and Health libraries are used interchangeably and refer to libraries providing library services to health care practitioners and students.

Questionnaire: “The questionnaire is the survey’s measuring instrument” (Statistics New Zealand, 1995 p. 41). “The term 'survey’ is often used interchangeably with 'questionnaire'; the two are not the same thing ... A questionnaire is a very specific data collection technique, which can be used within a variety of research methods” (Pickard, 2007 p. 95).

Reliability: "means that the survey or other instruments used are capable of producing consistent results” (Brophy, 2006 p. 14) and it is "the extent to which a measurement procedure yields the same answer however and whenever it is carried out” (Gorman \& Clayton, 2005 p. 54)". "Reliability is concerned with stability of the research findings over time and across locations. Typically test, re- 
test method is used to demonstrate reliability. The research is conducted more than once and by other researchers. If the results are found to be significantly similar then reliability is accepted.” (Pickard, 2007 p. 21).

Survey: "In essence a survey involves the collection of information from some (or all) units of a population using well-defined concepts, methods and procedures and the compilation of such information into a useful summary form” (Statistics New Zealand, 1995 p. 9) "A survey, then, is the research method used to structure the collection and analysis of standardized information from a defined population using a representative sample of that population.” (Pickard, 2007 p. 95).

Systematic reviews: “are review articles that are completed using predefined methods to minimize bias inherent to observational studies.” (McKibbon, 2006 p. 202) and they "consist of a scientific review of the literature intended to answer a focused question. Literature review search strategies for systematic reviews should be completely transparent so that a colleague could replicate the search to find the same cited literature” (Eldredge, 2006 p. 346).

Validity: "is the requirement that results should be accurate and that what has been measured is what was meant to be measured” (Brophy, 2006 p. 41). It is the truth of what is being measured; as Gorman and Clayton (2005 p. 54) put it: "Validity is the extent to which the measurement gives the correct answer”.

\subsection{Summary}

From this review of the literature on surveys and their instruments some conclusions can be drawn and hypotheses put forward about what this study will find in relation to the research questions asked about user surveys conducted by medical librarians. 
If user surveys in medical libraries are well designed with a clear research question and well defined population they can be a suitable research method to provide good quality evidence for decision making about library services.

Careful design is the key to a good quality survey. Pre-testing is an essential step in producing a well-designed questionnaire that will achieve good response rates.

It can be expected that print format surveys will have higher response rates than online-only surveys. It can reasonably be expected that the response rates from doctors will be lower than that of other groups surveyed.

Surveys employing proven methods to increase response rates, such as prenotification, personalised cover letters, and follow up will achieve a higher response rate than those that do not employ these methods. Surveys with fewer questions will achieve higher response rates than those with large numbers of questions and surveys that offer incentives will achieve higher response rates. Reporting of validity and reliability in medical library literature will be low; however, as confidentiality and ethical approval are considered important in a medical setting it is expected that surveys conducted in this environment will take care to report the ethical approval process and assure participants of confidentiality.

Reporting of survey research results in the library literature may be of variable quality as even in the medical literature research has revealed "only 51\% included a response rate, $8-16 \%$ provided access to the questionnaire, and $67 \%$ reported validation of the questions” (Burns et al., 2008 p. 251). If the reporting is not of a high standard the research may not be considered rigorous enough to be used in evidencebased practice, as research method must be transparent and reproducible. 


\section{$5 \quad$ Methodology}

A systematic review of the literature is the proposed methodology to answer the research question. In this context a systematic review is a qualitative integrated synthesis of a body of experience to gain an overview that can be used to make recommendations to improve survey design and increase survey response rates for user surveys carried out in medical libraries.

Although there have not been many systematic reviews of library research reported in the literature, "systematic reviews of research literature are now accepted as major contributors to the evidence base” (Brice \& Hill, 2004 p. 14).

McKibbon (2006) identifies the systematic review research method as both "observational and retrospective", as a systematic reviewer is observing the data (literature) and possibly uncovering patterns not previously recognised.

Mulrow describes systematic literature review as a fundamental scientific activity. Its rationale is grounded firmly in several premises” (Mulrow, 1994 p. 597)”.

Mulrow goes on to describe the rationale for systematic reviews as being a means of efficiently managing increasing amounts of information and integrating this information with existing knowledge to "provide data for rational decision making” (Mulrow, 1994 p. 597). "Researchers use the review to identify, justify, and refine hypotheses; recognize and avoid pitfalls of previous work; estimate sample sizes; and delineate important ancillary or adverse effects and covariates that warrant consideration in future studies” (Mulrow, 1994 p. 597).

It is recognized that good systematic reviews must take steps to minimize error and bias (Littell, Corcoran, \& Pillai, 2008). It is particularly important in this form of 
research as bias may occur at any stage of the original studies including, as has been discussed earlier, not only the original study but also in the "publication, dissemination and review processes and these biases can be cumulative” (Littell et al., 2008 p. 1).

The methodology of a systematic review is usually referred to as a protocol. A protocol for this systematic review was developed as part of the research proposal for this study. The protocol was reviewed by a supervisor and was followed as a plan for the research carried out. The protocol included the process to follow in selecting the studies to include in the review. It also outlined the criteria for appraising the included studies and how the results of the selection and appraisal were to be collated. "A protocol for carrying out a review is equivalent to, and as important as, a protocol for a primary research study” (Khan, Popay, \& Kleijnen, 2001 p. iii).

A comprehensive protocol for a conducting a systematic review should include the following components:

(a) the background to the systematic review;

(b) the review question;

(c) the search strategy and which sources are to be searched (and whether any resources will be searched by hand);

(d) the selection criteria for the studies to be included and the data extraction plan

(e) a synthesis of the extracted evidence; and

(f) a timetable of the project. 
The steps involved in conducting a systematic review are also identified by McKibbon (2006) as: a well defined question; a clearly described and reproducible search strategy; explicit inclusion and exclusion criteria to select the studies for review; a data extraction protocol; and data analysis. The steps necessary for a protocol have been followed in this research and are described in more detail below.

\subsection{Inclusion/exclusion criteria}

The reports of survey research to be included in this systematic review must be carried out in a medical library setting (academic medical library, hospital medical library or teaching hospital library) and be an investigation evaluating an existing library service or investigating a proposed new service to be provided by a medical library. It must include only self-completed web-based and postal surveys (not surveys administered in person or by telephone). Telephone follow-up is acceptable as long as the questions were not asked at this telephone follow-up.

The surveys should be related to a library service question but not be related to evaluating information literacy interventions, as a systematic review of this was conducted and published in 2003 and 2007 by Alison Brettle. (Brettle, 2003, 2007). Also excluded are studies that evaluate the impact of clinician librarians' interventions, again because there have been several recent reviews of these studies (Urquhart, Turner, Durbin, \& Ryan, 2007; Wagner \& Byrd, 2004; Winning \& Beverley, 2003).

Studies that report LibQUAL results are also excluded as there is extensive literature establishing the validity and reliability of LibQUAL. 


\section{$5.2 \quad$ Search strategy}

Literature searching for a systematic type of review must be comprehensive, as only by identifying all relevant studies can the reviewers ensure that bias is limited. It is also one of the things that distinguishes a systematic review from a traditional review where the articles are selected not using an object search strategy but rather are selected according to confirmation bias, i.e. those studies that fit with the point of view of the reviewer. It is also important that the search strategy is reported in such a way that it can be reproduced. A search of Ovid Medline, LISA, LISTA, and Scopus was made. The final searches for the review were carried out on the 13 February 2009.

A combination of subject heading (Medical Subject Headings or MESH) terms and keywords was used.

Table $1 \quad$ Search terms used in OVID Medline to locate studies

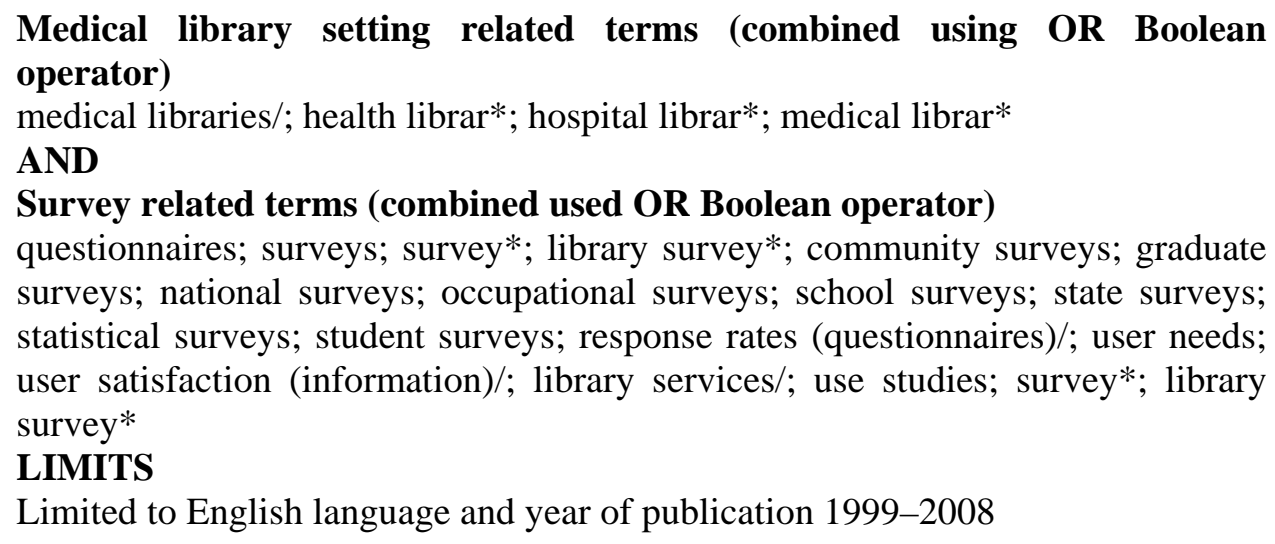


Table $2 \quad$ Keyword search terms used in SCOPUS to locate studies

\section{Medical library related terms (combined using OR Boolean operator)}

"medical librar*”; "hospital librar*”; "health librar*”

AND

Survey related terms

Survey*; questionnaire*

\section{LIMITS}

Limited to English language and year of publication 1999-2008

Table $3 \quad$ Keyword search terms used in LISTA locate studies

\section{Medical library related terms (combined using OR Boolean operator)}

“medical librar*”; "hospital librar*”; "health librar*”

\section{AND}

\section{Survey related terms}

Survey*; questionnaire*

\section{LIMITS}

Limited to Scholarly (peer reviewed) Journals and year of publication 1999-2008

*English language limit not available

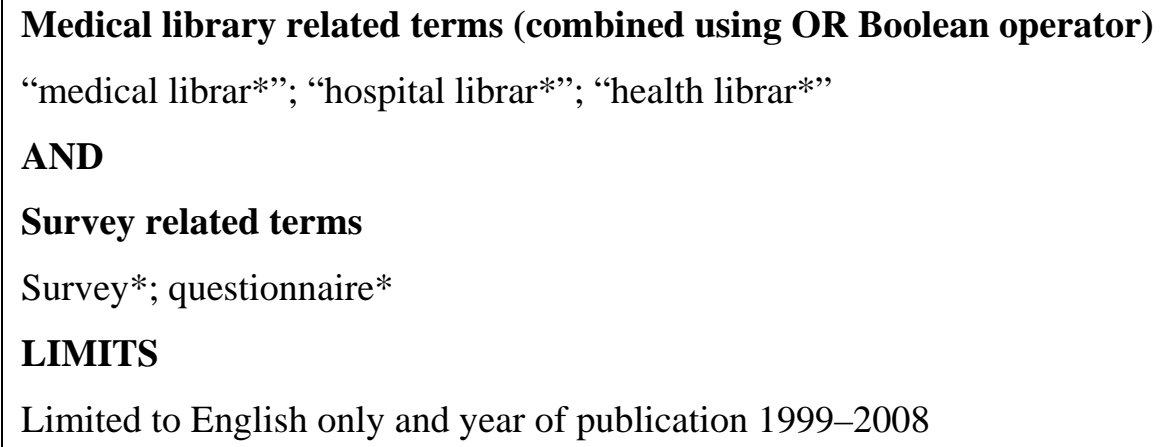


Two key medical library journals were also hand searched, i.e. Bulletin of the Medical Library Association (from 1997-2002) the Journal of the Medical Library Association (2002-2207) and the Health Libraries and Information Journal.

Articles were limited to those published in the English language. Although this has the potential to exclude some relevant studies the resources to translate original articles to enable data extraction are beyond the scope of this review.

The searches were also limited to the past ten years as it is only in this period that web-based surveys have been used. Searching further back would skew the results in favour of postal surveys.

The abstracts from the search results were screened using the inclusion and exclusion criteria ( $\mathrm{n}=162$ see figure 1 ). Those that appeared to fit the criteria were then retrieved in hard copy for further evaluation ( $\mathrm{n}=98$ see figure 1$)$.

At this stage 39 studies were excluded. The majority of these excluded studies were revealed to be surveys of medical librarians and medical libraries rather than the users of those libraries. This raises some interesting questions. If library measurement has evolved to focus on the library user (Kyrillidou \& Cook, 2008) as discussed earlier in the literature review, then why is so much research still focused on medical librarians and libraries? Is this the same for the rest of the library community or is it just in medical libraries? Does it reveal that the focus has not shifted as much as earlier suggest or other there other reasons at play? These questions are outside the scope of this study, however further research to explore these questions would be valuable. 
Figure $1 \quad$ Flow chart of study retrieval

Potentially relevant studies retrieved from

Medline $(n=220)$, Scopus $(n=326)$ LISTA

$(n=268)$, LISA $(n=255)$, hand searching $(n=64)$

Total $(n=1133)$

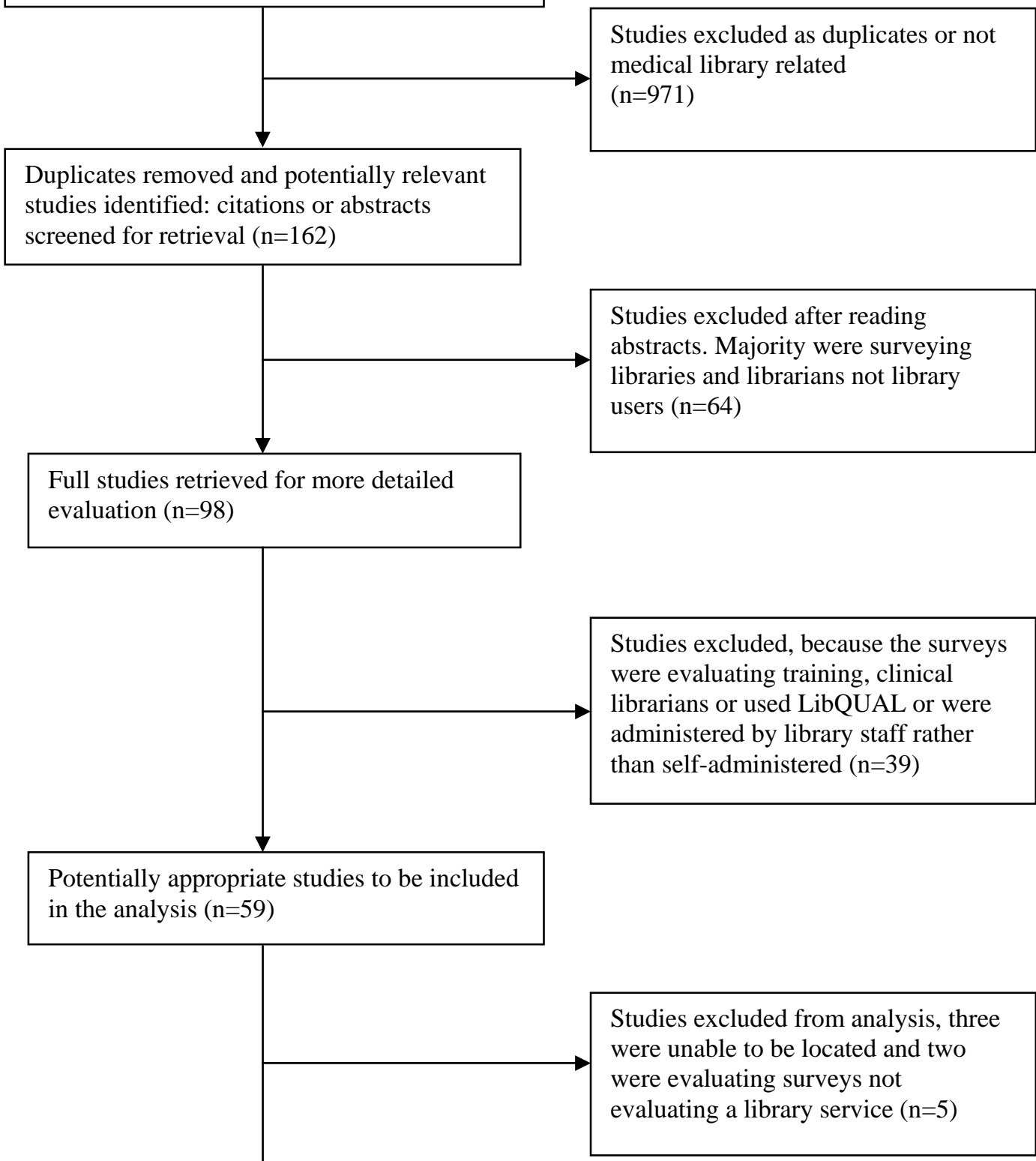

Studies with usable information $(n=54)$ 


\subsection{Methods of data analysis}

The data analysis method is one of data extraction. The following list outlines the data extracted from the studies identified as fitting the inclusion criteria described in above section:

Table $5 \quad$ Data extraction fields

\begin{tabular}{|c|c|}
\hline Author & Author \\
\hline Title & Title \\
\hline Year & $\begin{array}{l}\text { Year study reported (rather than } \\
\text { year carried out) }\end{array}$ \\
\hline Aims of study & As stated in report \\
\hline Key findings & As identified in report \\
\hline Survey method & As described in report print/online \\
\hline Pilot or pre-test & Was the survey pre-tested? \\
\hline Ethical approval & Was this sought? \\
\hline Location & Geographic location of library \\
\hline Setting & $\begin{array}{l}\text { Hospital/teaching } \\
\text { hospital/academic/other }\end{array}$ \\
\hline Population sample method & Random/non-random \\
\hline Survey delivery method & $\begin{array}{l}\text { Postal, in-person, pickup, emailed, } \\
\text { link on webpage etc? }\end{array}$ \\
\hline Pre-notification of survey? & Was this done and how? \\
\hline Cover letter? & Was this included? \\
\hline Personalised? & $\begin{array}{l}\text { Was the survey addressed to } \\
\text { individuals? }\end{array}$ \\
\hline Presentation of survey & $\begin{array}{l}\text { Coloured or white paper or other } \\
\text { distinguishing features e.g. size of } \\
\text { paper, or coloured ink etc. }\end{array}$ \\
\hline Sponsor of survey? & Who signed the letter or survey? \\
\hline Number of questions asked & Number of questions \\
\hline Types of questions & $\begin{array}{l}\text { Open or closed questions or } \\
\text { mixture? }\end{array}$ \\
\hline Total number of surveys sent & Total number of surveys sent \\
\hline $\begin{array}{l}\text { Total number of usable responses } \\
\text { received }\end{array}$ & $\begin{array}{l}\text { Total number of useable responses } \\
\text { received }\end{array}$ \\
\hline
\end{tabular}




\begin{tabular}{|l|l|}
\hline \% response rate & \% response rate \\
\hline Analysis method & $\begin{array}{l}\text { What was used to analyse the } \\
\text { results? }\end{array}$ \\
\hline Follow up & Yes/no \\
\hline Confidentiality guaranteed & Was this specifically mentioned? \\
\hline Incentives & $\begin{array}{l}\text { What was it and when was it } \\
\text { offered? }\end{array}$ \\
\hline Reliability discussed & $\begin{array}{l}\text { Was there a reported discussion of } \\
\text { instrument reliability ? }\end{array}$ \\
\hline Validity discussed & $\begin{array}{l}\text { Was there a reported discussion of } \\
\text { instrument validity? }\end{array}$ \\
\hline Limitations identified & $\begin{array}{l}\text { Were there any limitations } \\
\text { identified? }\end{array}$ \\
\hline Survey included in report? & Yes/no \\
\hline Survey available from authors? & Yes/no \\
\hline
\end{tabular}

The data was extracted into an Excel spreadsheet to allow analysis of results. It was not possible to attempt to conduct a meta-analysis as the studies were too heterogeneous. The aim was to conduct a qualitative synthesis of the literature of library user surveys to draw conclusions about how to increase response rates in the medical library setting and therefore increase the validity of the results and improve decision-making based on these results. 


\section{$6 \quad$ Results}

The comprehensiveness of reporting of survey results was lower than expected. None of the 54 studies identified could supply data for all of the extraction fields. The first authors and references to the 54 included studies are listed in Table 6.

Those surveys that had a higher standard of reporting, i.e. reported a greater number of the data elements and included more detail, were generally better quality surveys and achieved higher response rates.

There were 13 reported results, in 12 studies, for questionnaires that achieved response rates of $60 \%$ or over. The studies with the higher response rates confirmed the findings from the literature. All were print format surveys (one didn't report the format) and half reported using pre-testing and cover letters. The majority were carried out by academic medical libraries and none reported questionnaires with more than 30 questions. One surprising result was that only one of these high response rate surveys reported offering an incentive. These results are reported in more detail under each specific results section. 
1. Abromitis, R.A., E. Saghafi, and B.L. Folb, Assessing the information needs of psychiatric residents. Academic Psychiatry, 2003. 27(2): p. 100-3.

2. Alao, I.A., Students and overdue books in a medical library. Journal of the Medical Library Association, 2002. 90(3): p. 294-297.

3. Asemi, A. and N. Riyahiniya, Awareness and use of digital resources in the libraries of Isfahan University of Medical Sciences, Iran. Electronic Library, 2007. 25(3): p. 316-327.

4. Atlas, M.C., F. Garza, and R. Hinshaw, Use of laptop computers in an academic medical library. Medical Reference Services Quarterly, 2007. 26(2): p. 27-36.

5. Bardyn, T., C. Young, and L. Lombardi, How we surveyed doctors to learn what they want from computers and technology. Computers in Libraries, 2008. 28(1): p. 7-11.

6. Barnett, L., D. Cmor, and P. Morgan, Mediated Computer Search Services Relative to Instruction Services: A Survey of One Health Sciences Library. Medical Reference Services Quarterly, 2001. 20(2): p. 9-20.

7. Bertulis, R. and J. Cheeseborough, The Royal College of Nursing's information needs survey of nurses and health professionals. Health Information and Libraries Journal, 2008. 25(3): p. 186-197.

8. Blagden, P., The role of an NHS library service in the UK; The perceptions of clinical managers in Portsmouth, UK. Health Information and Libraries Journal, 2007. 24(2): p. 110-117.

9. Brookman, A., et al., What do clinicians want from us? An evaluation of Brighton and Sussex University Hospitals NHS Trust clinical librarian service and its implications for developing futureworking patterns. Health Information and Libraries Journal, 2006. 23(SUPPLEMENT 1): p. 10-21.

10. Cataldo, T.T., et al., Subject specialization in a liaison librarian program. Journal of the Medical Library Association, 2006. 94(4): p. 446-448.

11. Crawford, J., A study of issues in administering library services to nursing studies students at Glasgow Caledonian University. Health Information \& Libraries Journal, 2002. 19(2): p 90-7.

12. Crossno, J.E., et al., Assessment of Customer Service in Academic Health Care Libraries (ACSAHL): An instrument for measuring customer service. Bulletin of the Medical Library Association, 2001. 89(2): p. 170-176.

13. Crudge, S.E. and M.L. Hill, Electronic journal provision in a health-care library: Insights from a consultation with NHS workers. Health Information and Libraries Journal, 2006. 23(2): p. 87-94.

14. Davis, A., et al., A post-merger hospital library collection survey and data analysis indicated better resource allocation and user satisfaction. Journal of the Canadian Health Libraries Association, 2004. 25: p. 29-38.

15. De Groote, S. and M. Doranski, The use of personal digital assistants in the health sciences: results of a survey. Journal of the Medical Library Association, 2004. 92(3): p. 341-348.

16. Doney, L., Evaluating the impact of a project promoting library and information services to primary care in Nottingham, UK: Brief communication. Health Information and Libraries Journal, 2006. 23(1): p. 64-68.

17. Fikar, C.R. and L. Keith, Information needs of gay, lesbian, bisexual, and transgendered health care professionals: Results of an Internet survey. Journal of the Medical Library Association, 2004. 92(1): p. 56-65.

18. Haldane, G.C., LISTENing to healthcare students: the impact of new library facilities on the quality of services. Health information and libraries journal, 2003. 20 Suppl 1: p. 59-68.

19. Jackson, R., et al., The information requirements and information-seeking behaviours of health and social care professionals providing care to children with health care needs: A pilot study. Health Information and Libraries Journal, 2007. 24(2): p. 95-102.

20. Kananen, J., T. Ovaska, and J. Saarti, Collection policy management for the Kuopio University and Kuopio University Hospital, Finland: Detecting the needs of users and developing high-quality collections. Health Information and Libraries Journal, 2006. 23(3): p. 179-188.

21. Karpinski, J.L., Disconnected in a connected world: knowledge and understanding of Web 2.0 tools at the University of Pennsylvania Medical Center. Medical Reference Services Quarterly, 2008. 27(1): p. 53-72.

22. Karunanayake, C., User studies in libraries: Case study from a hospital library. Journal of Hospital Librarianship, 2007. 7(2): p. 31-46.

23. Komolafe, H.O. and A. Onatola, Information seeking habits of clinical information by nurses at Nigeria's Premier University Teaching Hospital: a survey. Journal of Hospital Librarianship, 2008. 8(2).

24. Korjonen-Close, H., The information needs and behaviour of clinical researchers: a user-needs analysis. Health information and libraries journal, 2005. 22(2): p. 96-106.

25. Lappa, E., Undertaking an information-needs analysis of the emergency-care physician to inform the role of the clinical librarian: a Greek perspective. Health information and libraries journal, 2005. 22(2): p. 124-132. 
26. Maheswari, U., Document delivery service at a Scottish primary care hospital library: Maria Henderson Library, Glasgow. Health information and libraries journal., 2005. 22(4): p. 286-290.

27. Mailer, L., The UK's SMARTAL Project: St MARTin's College health students Access to Learning resources whilst on placement. Health Information and Libraries Journal, 2006. 23(2): p. 110117.

28. Martin, S., Impact of a Graduate Entry Programme on a medical school library service. Health information and libraries journal, 2003. 20(1): p. 42-49.

29. Mawindo, D. and R. Hoskins, use of print and electronice resources by students at the University of Malawi College of Medicine. Mousaion, 2008. 25(1): p. 89-110.

30. McQuistan, S. and F. Schofield, User consultation in North Glasgow Libraries: a survey. SHINe Journal, 2006. 49.

31. Medernach, C. and J. Franko, Assessing the impact of information services in a regionalized healthcare organization. Health Information and Libraries Journal, 2007. 24(SUPPL. 1): p. 46-56.

32. Mi, M. and C.M. Gilbert, Needs assessment: Prerequisite for service excellence. Journal of Hospital Librarianship, 2007. 7(4): p. 31-52.

33. Oak, K. and R. Gegg, Increasing the rural general practitioners' use of library and information services through publicity: A randomized controlled trial in Cornwall, UK. Health Information and Libraries Journal, 2008. 25(3): p. 208-217.

34. Owen, D.J. and M.L.E. Fang, Information-seeking behavior in complementary and alternative medicine (CAM): An online survey of faculty at a health sciences campus. Journal of the Medical Library Association, 2003. 91(3): p. 311-321.

35. Paden, S., A. Batson, and R. Wallace, Web-based Loansome Doc, librarians, and end users:results from a survey of the Southeast Region. Bulletin of the Medical Library Association, 2001. 89(3): p. 263-271.

36. Pearson, D. and H. Rossall, Developing a general practice library: a collaborative project between a GP and librarian. Health information and libraries journal, 2001. 18(4): p. 192-202.

37. Perley, C.M., et al., Conducting a user-centered information needs assessment: The Via Christi Libraries' experience. Journal of the Medical Library Association, 2007. 95(2).

38. Renwick, S., Knowledge and use of electronic information resources by medical sciences faculty at The University of the West Indies. Journal of the Medical Library Association, 2005. 93(1): p. 21-31.

39. Rodman, R.L., Cost analysis and student survey results of library support for distance education. Journal of the Medical Library Association, 2003. 91(1): p. 72-8.

40. Sayed, E.N. and S.D. Murray, User Satisfaction Survey and Usage of an Electronic Desktop Document Delivery Service at an Academic Medical Library. Medical Reference Services Quarterly, 2003. 22(4): p. 21-29.

41. Schofield, F., Health Management Library and Information Service: literature search survey, 20042005. SHINe Journal, 2005. 47.

42. Shah, S., Digital Library services and their impact : a case of faculty of Health Sciences Library, Aga Khan University. Pakistan Library \& Information Science Journal, 2005. 36(3): p. 17-26.

43. Shaw-Kokot, J. and C. De la Varre, Using a journal availability study to improve access. Bulletin of the Medical Library Association, 2001. 89(1): p. 21-28.

44. Spak, J.M. and J.G. Glover, The personal librarian program: an evaluation of a Cushing/Whitney Medical Library outreach initiative. Medical reference services quarterly, 2007. 26(4): p. 15-25.

45. Tannery, N.H., et al., Use of Web-based library resources by medical students in community and ambulatory settings. Journal of the Medical Library Association, 2002. 90(3): p. 305-309.

46. Tennant, M.R., et al., Evaluation of a liaison librarian program: Client and liaison perspectives. Journal of the Medical Library Association, 2006. 94(4).

47. Thain, A. and A. Wales, Information needs of specialist healthcare professionals: a preliminary study based on the West of Scotland Colorectal Cancer Managed Clinical Network. Health Information \& Libraries Journal, 2005. 22(2): p. 133-42.

48. Turtle, K.M., A survey of users and non-users of a UK teaching hospital library and information service. Health information and libraries journal., 2005. 22(4): p. 267-275.

49. ur Rehman, S. and V. Ramzy, Awareness and use of electronic information resources at the health sciences center of Kuwait University. Library Review, 2004. 53(3): p. 150-156.

50. Urquhart, C., J. Durbin, and B. Cumbers, Evaluation of the KA24 (Knowledge Access 24) service for health and social care staff in London and the south-east of England. Part 2: Qualitative. Health Information and Libraries Journal, 2006. 23(3): p. 159-168.

51. Wallis, L., Information-seeking bahaviour of faculty in one school of public health. Journal of the Medical Library Association ( JMLA ), 2006. 94(4): p. 442-445.

52. Walton, L., et al., No more tours: How library tours of the past become today's celebrations. Medical Reference Services Quarterly, 2001. 20(1): p. 39-45.

53. Wandersee, J.R., Library check-up: medical residents and fellows' library questionnaire responses. Journal of Hospital Librarianship, 2008. 8(3): p. 323-331.

54. Yarfitz, S. and D.S. Ketchell, A library-based bioinformatics services program. Bulletin of the Medical Library Association, 2000. 88(1): p. 36. 


\subsection{Aims of surveys of studies}

All of the studies included had clearly-stated aims. Most of the aims were described in the abstract in sufficient detail to be able to easily extract the data for this field. The aims of the surveys reported in the studies were coded into four main categories:

1. awareness and use of existing library services;

2. assessment of user needs;

3. service evaluation and improvement;

4. collection development;

5. other.

Only one study fell outside these categories — a study that asked questions about library user perceptions of the importance of a subject background for liaison librarians (see Cataldo no.11 table 6).

Table $7 \quad$ Reported aims of study

\begin{tabular}{|l|l|l|}
\hline Aims of study & Number of studies & Percentage \% \\
\hline $\begin{array}{l}\text { 1.Awareness and use of existing } \\
\text { services }\end{array}$ & $(\mathrm{n}=21)$ & $38.9 \%$ \\
\hline 2. Assessment of user needs & $(\mathrm{n}=12)$ & $22.2 \%$ \\
\hline 3. Service evaluation and improvement & $(\mathrm{n}=17)$ & $31.5 \%$ \\
\hline 4. Collection development & $(\mathrm{n}=3)$ & $5.5 \%$ \\
\hline 5. Other & $(\mathrm{n}=1)$ & $1.9 \%$ \\
\hline Total & $(\mathrm{n}=54)$ & $100 \%$ \\
\hline
\end{tabular}


The studies in category 1 (“awareness and use of existing services”) were often the first step in a process to evaluate services with a longer term view to improve the services. They were the information-seeking aspect of the improvement process. The studies in category 2 (“assessment of user needs”) often preceded the establishment of a new service.

\subsection{Key findings}

Key findings were also clearly reported in all studies. The findings were varied and not able to be easily broken into categories. Several of the studies made more than one recommendation based on the information gathered from the questionnaires.

$89 \%$ of the studies analysed $(n=48)$ made recommendations for changes to services or introduction of new services based on the results of the survey research carried out. 11\% ( $n=6)$ studies did not make recommendations related to services but rather reported the increased understanding they had gained relating to the use of their services by the survey respondents. Very few of the reports made reference to low validity of their findings despite the fact that $13 \%(n=7)$ of the surveys reported response rates of $<20 \%$.

\subsection{Survey method and delivery}

Nearly $50 \%$ of the surveys reported were in "print format” only $(48.1 \% \mathrm{n}=26)$, with “online” the second highest category at $25.9 \%(n=14)$. Only $11.1 \%(n=6)$ reported the survey instrument being available in both print and online. 14.8\% ( $\mathrm{n}=8$ ) did not explicitly report the format of the survey.

It is interesting to note that of the 13 reports of response rates $>60 \%$ nearly all $(n=12)$ reported a print format (one was not reported). Conversely of the seven 
studies that reported response rates of $<20 \%$, four reported an online only format, one reported both print and online and two reported print formats. This appears to confirm claims that print format surveys outperform online surveys in terms of response rate.

Table $8 \quad$ Reported survey methods

\begin{tabular}{|l|l|l|}
\hline Survey method & number of studies & Percentage \% \\
\hline Print format & $(\mathrm{n}=26)$ & $48.1 \%$ \\
\hline Online & $(\mathrm{n}=14)$ & $25.9 \%$ \\
\hline Print and online & $(\mathrm{n}=6)$ & $11.1 \%$ \\
\hline Not reported & $(\mathrm{n}=8)$ & $14.8 \%$ \\
\hline Total & $(\mathrm{n}=54)$ & $100 \%$ \\
\hline
\end{tabular}

\subsection{Pilot or pre-test}

The majority, $63 \%(n=34)$ of the selected studies did not report pre-testing or piloting of the questionnaires used in the survey. Of the 37\% $(n=20)$ that reported pre-testing only $13 \%(n=7)$ gave any detail of who and how many it was tested on.

Of the 20 studies that reported pre-testing, academic medical libraries (50\% $\mathrm{n}=10$ ) and hospital libraries ( $35 \% \mathrm{n}=7$ ) were the setting most likely to have reported pre-testing of the questionnaires.

\subsection{Ethical approval and confidentiality}

An overwhelming majority of studies did not report ethical approval. $75.9 \%(n=41)$ of the articles selected for the study did not report whether ethical approval was gained 
for the study. $24.1 \%(n=13)$ of the studies reported gaining ethical approval for the survey. The assumption that hospitals, because of their awareness of patient rights and high value placed on ethics, would be as likely as academic setting to seek ethical approval was substantiated. Six (46.1\%) of the 13 studies that reported ethical approval were carried out in a hospital setting and the remaining seven (53.8\%) were carried out in an academic setting.

\subsection{Location and setting}

As expected the most of the included studies were from locations in either the United States (USA) or in the United Kingdom (UK). This was expected because the two major journals in the medical library area are the Journal of Health Libraries and Information (which is a UK-based journal) and the Journal of the Medical Library Association (which is a US-based journal). The fact that the search strategy excluded studies not published in English also skewed the studies retrieved in favour of articles from English-speaking countries.

$40.7 \%(n=22)$ of the studies were carried out in a US location and 35.2\% $(n=19)$ were carried out in a UK location. The remaining 13 studies were split between Canada 5.5\% (n=3), Nigeria 3.7\% $(n=2)$ and Australia, Kuwait, Iran, Finland, Greece, South Africa, West Indies and Pakistan all with 1.8\% $(\mathrm{n}=1)$.

The majority of studies were carried out in an academic or medical library. 53.7\% $(n=29)$ were carried out in academic libraries and 35.2\% $(n=19)$ were carried out in a hospital library setting. There were 5.5\% $(n=3)$ studies carried out a teaching hospitals, i.e. those hospitals providing training for medical students. There were another $5.5 \%$ of the studies that fell into the "other" category - two studies were 
carried out on professional groups (nurses and clinical researchers) and the third was carried out in a general practice setting.

$89.7 \%$ ( $n=26)$ of the 29 studies carried out in an academic medical library setting reported response rates. The average reported response rate for questionnaires in an academic library setting was $50.1 \%$. $68.4 \%(n=13)$ of the 19 studies carried out in a hospital library reported response rates. The average reported response rate for questionnaires in a hospital library setting was $40.8 \%$.

Table $9 \quad$ Setting for the reported studies

\begin{tabular}{|l|l|l|}
\hline Setting & Number of studies $(\mathbf{n}=\mathbf{5 4})$ & Percentage \% \\
\hline $\begin{array}{l}\text { Academic medical } \\
\text { library }\end{array}$ & $(\mathrm{n}=\mathbf{2 9})$ & $53.8 \%$ \\
\hline Hospital library & $(\mathrm{n}=19)$ & $35.2 \%$ \\
\hline Teaching hospital & $(\mathrm{n}=3)$ & $5.5 \%$ \\
\hline Other & $(\mathrm{n}=3)$ & $5.5 \%$ \\
\hline Total & $(\mathrm{n}=54)$ & $100 \%$ \\
\hline
\end{tabular}

\subsection{Population sample method and exclusions}

The reporting of how the population to be surveyed was disappointing. It is one of the most important aspects of reporting any survey and yet in $7.4 \%(n=4)$ of studies it was not reported at all. $61.1 \%(n=33)$ of the studies reported using a non-probability sampling method. 
Table 10 Sampling methods

\begin{tabular}{|l|l|l|}
\hline Type of sampling & Number of studies $\mathbf{n}=$ & Percentage \% \\
\hline Non-probability & $(\mathrm{n}=33)$ & $61.1 \%$ \\
\hline Probability & $(\mathrm{n}=7)$ & $12.9 \%$ \\
\hline Census & $(\mathrm{n}=10)$ & $18.6 \%$ \\
\hline Not reported & $(\mathrm{n}=4)$ & $7.4 \%$ \\
\hline Total & 54 & $100 \%$ \\
\hline
\end{tabular}

When surveys attempt to capture information from all the individuals belonging to a particular group it is no longer a survey but becomes instead a census. Although a number of the studies reported claimed to be surveying “all” members of a specified group, when considered with the type of survey it became apparent that this claim was made for survey instruments that were in the main distributed via email. The individuals who chose to respond to an online survey become in effect a self-selecting sample.

\subsection{Pre-notification, cover letter and sponsor}

This was the most disappointing aspect of this review of survey studies. For these four data elements there was almost no reported data.

Only five studies (9.2\%) reported any pre-notification of the survey to the intended sample population and of those five studies only two included any detail regarding the method of pre-notification.

The reporting of use of a cover letter was also disappointing. $66.6 \%(n=36)$ of the studies did not report including a cover letter with the questionnaire. The remainder 
$(n=18)$ reported including a cover letter. One stated that it fact that it was included in the email (De Groote no. 17). Of the 18 cover letters reported only three (16.6\%) reported being personalized despite the fact that personalizing cover letter is proven to improve response rates. Only three studies $(5.5 \% \mathrm{n}=3)$ reported any information about the sponsor of the survey and only two of these reported response rates. There was therefore not enough data extracted to draw any conclusions about the effect of the sponsor on response rates.

\subsection{Survey presentation}

There was no information reported about the presentation of the survey instrument in $83 \%(n=45)$ of the studies included. A brief comment about the length of the survey e.g. "kept it short" (Crudge no. 14 see table 6) was made in 7.4\% (n=4) of the studies.

Less than $10 \%(9.2 \% \mathrm{n}=5)$ made more substantial comments about the presentation of the survey instrument. Two of the comments are included here “design was concise and presented on a single side of A4 coloured paper. Tone was friendly and layout simple” (Oak et al no. 34 see table 6) and “consideration given to various methods to increase response rate, e.g. use of coloured paper, recommended maximum length, time required to complete, multiple choice versus text boxes. Designed with multiple choice answers, as few text boxes as possible and limited to 4 sides of A4” (Thain et al no. 49 see table 6).

None of the studies that reported information about the presentation of the questionnaire reported response rates of over $60 \%$.

With so few of the included studies reporting information about the presentation of the questionnaires it is not possible to draw any conclusions about presentation features that could enhance response rates. 


\subsection{Number and type of questions asked}

As Brettle (2003) found in her review of information skills training, large numbers of studies did not include the questionnaires in their reports and "with each study seemingly having developed its own questionnaire rather than using a pre-validated tool or validation of the questionnaire” (Brettle, 2007 p. 6).

Where the number of questions was not stated but the survey was included in the appendices the questions were counted and included in the data. This still left $42.5 \%$ $(n=23)$ of reports that did not state the number of questions. In five of these cases the questionnaire was available from the author; however attempts to contact authors were unsuccessful (email addresses were not valid). Of the 23 that didn't report the number of questions 14 were print only, three online only, four didn't report the format and two were available in both print and online formats.

The number of questions or items in the survey instrument were reported in $25.9 \%(n=14)$ of print format only surveys. Two questions was the lowest number reported and 48 the highest. The average number of questions for print surveys was 16.9 questions.

The number of questions asked was reported in $18.5 \%(n=10)$ of online only surveys. The lowest number of questions asked online was one and the highest 45 . The average number of questions asked online was 14.5.

\subsection{Response rates}

Three "print format" only surveys did not report a response rate at all $(n=26-3)$ but in four articles two surveys were reported each with separate response rates $(n=23+4)$ to 
give a total of 27 response rates reported for print format surveys. The response rates ranged from $13 \%$ to $100 \%$. The average response rate for print format surveys was $53.5 \%$.

Of the online-only surveys, 12 reported response rates. The response rates ranged from a low of $8 \%$ to a high of $50 \%$. The average response rate for online-only was $25.5 \%$.

Of the surveys in both print and online formats $50 \%(n=3)$ were not able to report response rates. This suggests a difficulty with administering both formats, it is almost impossible to know how many potential respondents received the survey instrument and therefore it is impossible to determine the response rate. The remaining three reported rates of $2.8 \%, 22 \%$ and $55 \%$. No conclusions can be drawn from such a small number or such a wide range of results.

Table 10 Response rates by format

\begin{tabular}{|l|l|l|}
\hline Response rates by format & $\begin{array}{l}\text { No. of studies reporting } \\
\text { response rates }\end{array}$ & $\begin{array}{l}\text { Average response } \\
\text { rate \% }\end{array}$ \\
\hline Print format & 27 & $53.5 \%$ \\
\hline Online format & 12 & $25.5 \%$ \\
\hline Print and online & 3 & Not calculated \\
\hline
\end{tabular}

Thirteen results (12 studies, one study reported results of two questionnaires) reported response rates of over $60 \%$. $92 \%(n=12)$ of these studies reported using a print format questionnaire and $8 \%(n=1)$ did not report the format of the questionnaire. $50 \%(n=6)$ of the print format surveys that achieved high response rates were distributed in person to the participants. $41.6 \%(n=5)$ were delivered by 
post and one of the high response rate studies did not report delivery method. In contrast $71 \%(n=5)$ of the seven studies that reported responses rates of below $20 \%$ were delivered by email.

A majority, $71.4 \%(n=30)$ of the surveys that reported response rates $(n=42)$ had rates of $<60 \%$. Of these, $16.6 \%(n=7)$ reported response rates of less than $20 \%$. It would not be possible to generalise results from these studies unless extensive work has been done to ensure that non-responder bias was not present.

\subsection{Follow- up}

Although follow-ups are strongly recommended in the literature, the information reported about follow-up timing and method for the selected studies was poor. $76 \%$ $(n=41)$ of the studies did not report any information regarding reminders. Only $24 \%$ $(n=13)$ reported information about follow-ups or reminders. Five of the studies that followed up with reminders gave details about the timing and method, the rest simply reported that a follow-up had occurred. Of the studies that reported follow-ups $(n=13)$ two did not report response rates. The response rates for the remaining 11 studies ranged from $8 \%$ to $72 \%$. There is not enough reported information regarding followup from the selected studies to draw any conclusions about the impact on response rates.

\subsection{Incentives}

Given the strong evidence for the impact of incentives on increasing response rates it was surprising that only $11 \%(n=6)$ of the studies $(n=54)$ reported offering an incentive. $87 \%(n=47)$ of the studies did not report any information regarding 
incentives and one study (1.8\%) reported explicitly that no incentive was offered. Two of the six studies reporting incentives gave no detail of the incentive. One study reported offering a free thumb drive, one a bottle of champagne, one a free computer search and one study reported an extensive package — "pen with the Via Christi Libraries logo and Web address, a free soda, a cookie, and a chance to register for a \$50 grand prize gift certificate” (Perley et al no. 38 see table 6). Once again the number of studies reporting details of incentives offered is too small to draw any conclusions about the relationship to response rates.

Limited budgets may be the explanation for the small number of studies that reported offering incentives.

\subsection{Validity and reliability}

Only one study discussed validity and that was in relation to pilot testing "to obtain a measure of face validity” (Tennant et al. no.48). This was not unexpected and even in the medical literature, where there is the expectation of great rigor in reporting questionnaire results, it has been shown that rates of less than $70 \%$ exist for reporting validation of the questions (Burns et al., 2008 p. 251). It does, however, raise questions about the quality of information obtained from these surveys. This study has found that very few of the surveys investigated content validity by pre-testing survey instruments or using instruments that have already been tested and shown to be valid. Only 37\% (n=20) of the 54 studies reported pre-testing.

External validity is another important factor to consider particularly with survey design. None of the identified studies discussed reliability at all. Again this is something that could and should be addressed by pre-testing. Even in those studies that did pre-test, reliability of the survey instrument was not explicitly discussed. This 
leaves the possibility that the instruments were not reliable and again calls into question the quality of the data obtained from the surveys.

\subsection{Limitations}

Just under half of the studies, $48.1 \%(n=26)$, reported some limitations. Some studies reported more than one limitation. There were 31 limitations coded into five categories:

1. low response rate;

2. sample issues;

3. instrument issues;

4. delivery issues;

5. other.

\begin{tabular}{|l|l|l|}
\hline Limitation categories & No. of limitations (n=31) & \% \\
\hline Low response rate & 10 & $32.3 \%$ \\
\hline Sample issues & 6 & $19.4 \%$ \\
\hline Instrument issues & 9 & $29 \%$ \\
\hline Delivery issues & 5 & $16.1 \%$ \\
\hline Other & 1 & $3.2 \%$ \\
\hline Total & 31 & $100 \%$ \\
\hline
\end{tabular}

Issues of low response rates and instrument issues such as the questionnaire being too long made up the majority of the limitations reported with $32.3 \%(n=10)$ and $29 \%$ 
( $\mathrm{n}=90$ respectively. Other issues such as delivery related to problems with online surveys and internet access and timing of the survey. The "other" limitation reported was incomplete answers to questions. It can be seen from the reported limitations that steps to increase response rates would have the potential to reduce the reported limitations in medical library user surveys. 


\section{Discussion}

While surveys continue to be a popular research tool for medical librarians more care should be taken in the design and presentation of the questionnaires used in surveys.

The quality of reporting methodology and results from surveys conducted in medical and hospital library setting is disappointing low. Medical libraries have been at the forefront of helping to develop evidence-based practice in librarianship. (Eldridge, Booth). They are in a key position to be leading the way in producing high quality research that adds to the body of knowledge for the profession. A key component of good quality research is good reporting. Several guidelines have been developed in the medical literature to help improve the quality of research reporting, as the medical profession recognised that without good reporting of the research the ability to put in place evidence-based practice was severely limited. CONSORT is probably the most recognized of these guidelines and is described as:

a checklist of items that should be included in the publication of a randomizedcontrolled trial. The checklist items require clear and thorough descriptions of hypothesis, protocol, randomization, blinding, follow-up and analysis; full details are available at www.consort-statement.org. As far as possible, items are evidence-based i.e. included if evidence supports their use. (Needleman 2000 p. 61.)

It seems reasonable to expect that similar guidelines or checklists should be recommended for the reporting of survey research in the library literature. There have also been standards developed for reporting quantitative systematic reviews: 
The systematic review movement has already driven the development of standards to improve the quality of reporting of quantitative systematic reviews (e.g. QUOROM and MOOSE). Such standards make it easier for readers to assess the quality of such reviews and for researcher to replicate their methods. (Booth 2006 p. 425.)

The quality of reporting survey research in the medical library literature is crucial to the development of the evidence base on which to base decisions and it is "only with sufficient detail and transparent reporting of the survey's methods and results can readers appraise the survey’s validity” (Burns et al. p. 251).

To provide some guidance to medical librarians reporting survey results a checklist has been developed. Development of "Reporting Survey Results Guidelines" (Resurge) was informed by the literature review and results of this study. It has not been validated beyond this study.

Following the "Resurge" guidelines as a minimum reporting structure would greatly improve the quality of survey evidence available in the medical literature. 


\subsection{Reporting Survey Results Guidelines (Resurge)}

\begin{tabular}{|c|c|c|}
\hline 1. Preparation & Aim & $\begin{array}{l}\text { What are the objectives of the } \\
\text { survey? They should be stated } \\
\text { clearly. }\end{array}$ \\
\hline & Context & Study setting and population \\
\hline & $\begin{array}{l}\text { Ethical approval } \\
\text { process }\end{array}$ & $\begin{array}{l}\text { If not required state this. } \\
\text { Include informed consent process } \\
\text { (participants need to be told how long } \\
\text { the survey will take, what data will } \\
\text { be stored and for how long, who is } \\
\text { carrying out the research and what } \\
\text { for?) } \\
\text { Include confidentiality and data } \\
\text { protection mechanisms }\end{array}$ \\
\hline \multirow[t]{4}{*}{ 2. Methods } & $\begin{array}{l}\text { Design and pre- } \\
\text { testing }\end{array}$ & $\begin{array}{l}\text { How was the instrument designed? } \\
\text { Include description of development } \\
\text { and pre-testing processes }\end{array}$ \\
\hline & Pre-notification? & $\begin{array}{l}\text { Was there any pre-notification of the } \\
\text { survey? How was this done? Include } \\
\text { wording in appendix if possible. }\end{array}$ \\
\hline & Sampling & $\begin{array}{l}\text { Convenience, } \\
\text { randomised. } \\
\text { If randomised was it systematic } \\
\text { sampling or stratified sampling? } \\
\text { Explain reasons for choice of } \\
\text { sampling. } \\
\text { Describe how potential participants } \\
\text { were identified and how they were } \\
\text { contacted. }\end{array}$ \\
\hline & Sample size & $\begin{array}{l}\text { Explicit state the sample size and } \\
\text { justify the size of the sample. }\end{array}$ \\
\hline \multirow[t]{3}{*}{ 3. Administration } & Format of survey & $\begin{array}{l}\text { Print or web/email? If online was it } \\
\text { sent out email or on a website? }\end{array}$ \\
\hline & Data collection & $\begin{array}{l}\text { How were the responses captured? } \\
\text { Were they manually entered or was } \\
\text { there an automatic method? }\end{array}$ \\
\hline & $\begin{array}{l}\text { Distribution and } \\
\text { return }\end{array}$ & $\begin{array}{l}\text { If print how were the surveys } \\
\text { distributed? Post or internal mail? } \\
\text { How were they returned? Was there a } \\
\text { pre-addressed, pre-paid envelope or }\end{array}$ \\
\hline
\end{tabular}




\begin{tabular}{|c|c|c|}
\hline & & were they sent back via internal mail. \\
\hline & $\begin{array}{l}\text { Were incentives } \\
\text { offered? }\end{array}$ & $\begin{array}{l}\text { What was offered? i.e. monetary or } \\
\text { non-monetary? How? i.e. sent out } \\
\text { with survey or on completion or in } \\
\text { the draw for a prize? }\end{array}$ \\
\hline & Timeframe? & $\begin{array}{l}\text { Over what timeframe was the data } \\
\text { collected? Does that include any } \\
\text { follow-up period? } \\
\text { Were any late responses included or } \\
\text { excluded? }\end{array}$ \\
\hline & Reminders? & $\begin{array}{l}\text { Were reminders sent? When, how } \\
\text { many, and how many responses } \\
\text { occurred after each reminder? }\end{array}$ \\
\hline & Print format & $\begin{array}{l}\text { Include colour and size of paper, and } \\
\text { colour of print, number of pages }\end{array}$ \\
\hline & Cover letter & $\begin{array}{l}\text { Was it separate to survey or part of } \\
\text { it? Who signed it? } \\
\text { Affiliation of survey sponsor. }\end{array}$ \\
\hline & Web format & $\begin{array}{l}\text { Number of screens. } \\
\text { Can participants review and change } \\
\text { answers? }\end{array}$ \\
\hline & Questions & $\begin{array}{l}\text { Number of items? } \\
\text { Type of questions, i.e. open or } \\
\text { closed? Rating scales or multichoice? } \\
\text { Important to include the } \\
\text { questionnaire as part of the report or } \\
\text { if that is not possible that it can be } \\
\text { obtained from the author. }\end{array}$ \\
\hline 4. Results & Response rates & $\begin{array}{l}\text { Report number of responses and } \\
\text { number of complete responses. } \\
\text { Describe and justify any responses } \\
\text { not included in the analysis of the } \\
\text { data. Can the results be generalised to } \\
\text { the population being considered? }\end{array}$ \\
\hline & Data analysis & $\begin{array}{l}\text { Describe and justify the method of } \\
\text { data analysis. } \\
\text { List any software packages used. }\end{array}$ \\
\hline 5. Discussion & $\begin{array}{l}\text { Limitations of the } \\
\text { survey }\end{array}$ & $\begin{array}{l}\text { Ensure that any limitations of the } \\
\text { survey are clearly described with } \\
\text { recommendations for how it could be } \\
\text { improved. }\end{array}$ \\
\hline
\end{tabular}




\subsection{Limitations of this study}

Only one researcher reviewed against the inclusion/exclusion criteria; this leaves the possibility of bias. Time limitations mean the scope of the review had to be limited to ensure a manageable number of studies were retrieved and reviewed. As McKibbon states:

Systematic reviews take considerable time and resources to complete ... many graduate schools offer courses on systematic reviews and meta-analysis and estimate that it would take approximately 600 hours to complete a narrowly focused review using a team of two or five reviewers. (McKibbon, 2006 p. 208)

This review has not addressed issues to do with completeness of responses. This is another issue of questionnaire design and is outside the scope of this review. 


\section{Conclusions}

User surveys in medical libraries are a potential source of good evidence and can add to the body of knowledge but only if they are well designed and well reported.

Librarians should seek expert help when designing user surveys. They should use the extensive evidence in the medical and library literature to improve survey design and use methods such as pre-notification, personalised cover letters and shorter questionnaires to improve response rates. They should be aware that print format surveys have better response rates than online surveys and incentives offered at the time of the survey can increase responses.

The study has also drawn attention to the importance of comprehensive reporting when publishing the results of survey research in the literature. Without clear and transparent reporting it is not possible to easily assess the quality of the research. To provide guidance for reporting survey research a checklist was developed. “Reporting Survey Results Guidelines" (Resurge) is provided as a minimum guideline for reporting survey results.

If survey research is well designed and well reported then the answer to the research question, “are user surveys able to provide good quality evidence for decision making about library services in medical libraries?”, is “yes”. With well-designed user surveys medical libraries are able to provide good quality evidence for decisionmaking about library services. 


\section{References}

Beebe, T. J., Stoner, S. M., Anderson, K. J., \& Williams, A. R. (2007). Selected questionnaire size and color combinations were significantly related to mailed survey response rates. Journal of Clinical Epidemiology, 60(11), 1184-1189.

Booth, A. (2003). A quest for questionnaires. Health Information and Libraries Journal, 20(1), 53-56.

Booth, A. (2005). Mind your Ps and Qs (pitfalls of questionnaires). Health Information and Libraries Journal, 22(3), 228-231.

Booth, A., \& Brice, A. (2004). Why evidence-based information practice? In A. Booth \& A. Brice (Eds.), Evidence Based Practice for Information Professionals: A handbook. London: Facet.

Brettle, A. (2003). Information skills training: a systematic review of the literature. Health Information \& Libraries Journal, 20(s1), 3-9.

Brettle, A. (2007). Evaluating information skills training in health libraries: a systematic review. Health Information and Libraries Journal, 24(s1), 18-37.

Brice, A., \& Hill, A. (2004). A brief history of evidence-based practice. In A. Booth \& A. Brice (Eds.), Evidence Based Practice for Information Professionals: A handbook. London: Facet.

Brophy, P. (2006). Measuring library performance: principles and techniques. London: Facet Publishing.

Burkell, J. (2003). The dilemma of survey nonresponse. Library \& Information Science Research, 25(3), 239-263.

Burns, K. E. A. M. D. M., Duffett, M. B., Kho, M. E. P. T. M., Meade, M. O. M. D. M., Adhikari, N. K. J. M. M., Sinuff, T. M. D. P., et al. (2008). A guide for the design and conduct of self-administered surveys of clinicians. CMAJ, 179(3), 245-252.

Charbonneau, D. H. (2007). Demystifying Survey Research: Practical Suggestions for Effective Question Design. Evidence Based Library and Information Practice, 2(4), 46-56.

Cochrane Collaboration. (2009). Cochrane Review Groups (CRGs) Retrieved 9th March, 2009, from http://www.cochrane.org/contact/entities.htm\#CRGLIST

Crumley, E., \& Koufogiannakis, D. (2002). Developing evidence-based librarianship: practical steps for implementation. Health Information and Libraries Journal, 19(2), 61-70.

Cullen, R. (2001). Perspectives on user satisfaction surveys. Library Trends, 49(4), 662-686.

Draugalis, J. L. R., Coons, S. J., \& Plaza, C. M. (2008). Best practices for survey research reports: a synopsis for authors and reviewers. American Journal of Pharmaceutical Education, 72(1), 1- 6. 
Drummond, F. J., Sharp, L., Carsin, A.-E., Kelleher, T., \& Comber, H. (2008). Questionnaire order significantly increased response to a postal survey sent to primary care physicians. Journal of Clinical Epidemiology, 61(2), 177-185.

Edwards, P., Roberts, I., Clarke, M., DiGuiseppi, C., Pratap, S., Wentz, R., et al. (2002). Increasing response rates to postal questionnaires: systematic review. British Medical Journal, 324(7347), 1183.

Edwards, P., Roberts, I., Clarke, M., DiGuiseppi, C., Pratap, S., Wentz, R., et al. (2005). Methods to influence response to postal questionnaires (Cochrane Methodology Review). The Cochrane Library(1).

Edwards, P., Roberts, I., Clarke, M., DiGuiseppi, C., Pratap, S., Wentz, R., et al. (2007). Methods to influence response to postal questionnaires (Cochrane Methodology Review). Cochrane Database of Systematic Reviews(2).

Eldredge, J. (2000). Evidence-based librarianship: an overview Bulletin of the Medical Library Association, 88(4), 289-302.

Eldredge, J. (2004). How good is the evidence base? In A. Booth \& A. Brice (Eds.), Evidence-Based Practice for Information Professionals: a Handbook. London: Facet Publishing.

Eldredge, J. (2006). Evidence-based librarianship: the EBL process. Library Hi Tech, 24(3), 341-354.

Fineout-Overholt, E., \& Johnston, L. (2005). Teaching EBP: Asking Searchable, Answerable Clinical Questions. Worldviews on Evidence-based Nursing, 2(3), 157-160.

Hayslett, M. M., \& Wildemuth, B. M. (2004). Pixels or pencils? The relative effectiveness of Web-based versus paper surveys. Library \& Information Science Research, 26(1), 7393.

Hernon, P., \& Calvert, P. J. (1996). Methods for measuring service quality in university libraries in New Zealand. The Journal of Academic Librarianship, 22(5), 387-391.

Hernon, P., \& Schwartz, C. (2000). Editorial Survey Research: A Time for Introspection. Library \& Information Science Research, 22(2), 117-121.

Hider, P., \& Pymm, B. (2008). Empirical research methods reported in high-profile LIS journal literature. Library \& Information Science Research, 30(2), 108-114.

Johnson, D. T. (1995). Focus on the Library Customer: Revelation, Revolution, or Redundancy? Library Trends, 43(3), 318-325.

Kelley, K., Clark, B., Brown, V., \& Sitzia, J. (2003). Good practice in the conduct and reporting of survey research. International Journal for Quality in Health Care, 15(3), 261-266.

Khan, K. S., Popay, J., \& Kleijnen, J. (2001). Stage 1 Planning the review: Phase 2 Development of a review protocol. In Undertaking systematic reviews of research on effectiveness: CRD's guidance for those carrying out or commissioning reviews (2nd ed.): NHS Centre for Reviews and Dissemination, University of York. 
Kuruppu, P. U. (2007). Evaluation of Reference Services--A Review. The Journal of Academic Librarianship, 33(3), 368-381.

Kyrillidou, M., \& Cook, C. (2008). The Evolution of Measurement and Evaluation of Libraries: A Perspective from the Association of Research Libraries. Library Trends, 56(4), 888-909.

Lee, D. (2004). Survey research; reliability and validity. Library Administration \& Management, 18(4), 211-212.

Littell, J., Corcoran, J., \& Pillai, V. (2008). Systematic reviews and meta-analysis. New York: Oxford University Press.

Littleton, D. (2007). Navigating pitfalls of web-based survey development and administration. Medical Reference Services Quarterly, 26(4), 75-83.

Marshall, J. G. (2007). Measuring the value and impact of health library and information services: past reflections, future possibilities. Health Information and Libraries Journal, 24(s1), 4-17.

McKibbon, K. A. (2006). Systematic reviews and librarians. Library Trends, 55(1), 202-215.

Miller, L. (2004). User satisfaction surveys. Aplis, 17(3), 125-133.

Mulrow, C. D. (1994). Systematic reviews: rationale for systematic reviews. British Medical Journal, 309, 597-599.

Needleman, I. (2000). Is this good research? Look for CONSORT and QUORUM. Evidence-Based Dentistry, 2(3), 61-62.

New Zealand Cochrane Fellow. (2009). New Zealand Branch of the Australasian Cochrane Centre Retrieved 8th March, 2009, from http://www.cochrane.org.nz/

Nulty, D. D. (2008). The Adequacy of Response Rates to Online and Paper Surveys: What Can Be Done? Assessment \& Evaluation in Higher Education, 33(3), 1-13.

Olmsted, M. G., Murphy, J., McFarlane, E., \& Hill, C. A. (2005). Evaluating Methods for Increasing Physician Survey Cooperation. Paper presented at the 60th Annual Conference of the American Association for Public Opinion Research (AAPOR).

Panacek, E. A. (2008). Survey-based research: Performing the survey. Air Medical Journal, 27(2), 64-66.

Pickard, A. J. (2007). Research methods in information. London: Facet.

Powell, R. R., \& Connaway, L. S. (2004). Basic research methods for librarians (4th ed.): Ablex Pub.

Presser, S., Couper, M. P., Lessler, J. T., Martin, E., Martin, J., Rothgeb, J. M., et al. (2004). Methods for testing and evaluating survey questions. Public Opinion Quarterly, 68(1), 109-130.

Rosen, T., \& Olsen, J. (2006). Invited commentary: the art of making questionnaires better. American Journal of Epidemiology, 164(12), 1145-1149. 
Rossall, H., Boyes, C., Montacute, K., \& Doherty, P. (2008). Developing research capacity in health librarians: a review of the evidence. Health Information \& Libraries Journal, 25(3), 159-174.

Sackett, D. L., Rosenberg, W. M. C., Gray, J. A. M., Haynes, R. B., \& Richardson, W. S. (1996). Evidence based medicine: what it is and what it isn't. British Medical Journal, 312(7023), 71-72.

Sampson, M., Daniel, R., Cogo, E., \& Dingwall, O. (2008). Sources of evidence to support systematic reviews. Journal of the Medical Library Association, 96(1), 66-69.

Smeeth, L., \& Fletcher, A. E. (2002). Improving the response rates to questionnaires Several common sense strategies are effective. British Medical Journal, 324(7347), 11681169.

Straus, S. E., Richardson, W. S., Glasziou, P., \& Haynes, R. B. (2005). Evidence-based medicine : how to practice and teach EBM (3rd ed.). Edinburgh: Churchill Livingstone.

Totten, V. Y., Panacek, E. A., \& Price, D. (1999). Basics of research (part 14) survey research methodology: Designing the survey instrument. Air Medical Journal, 18(1), 26-34.

Urquhart, C., Turner, J., Durbin, J., \& Ryan, J. (2007). Changes in information behavior in clinical teams after introduction of a clinical librarian service. Journal of the Medical Library Association, 95(1), 14.

VanGeest, J. B., Johnson, T. P., \& Welch, V. L. (2007). Methodologies for Improving Response Rates in Surveys of Physicians: A Systematic Review. Evaluation \& the Health Professional, 30(4), 303-321.

Wagner, K. C., \& Byrd, G. D. (2004). Evaluating the effectiveness of clinical medical librarian programs: a systematic review of the literature. Journal of the Medical Library Association, 92(1), 14.

Winning, M. A., \& Beverley, C. A. (2003). Clinical librarianship: a systematic review of the literature. Health Information \& Libraries Journal, 20(s1), 10-21. 